\title{
NATIONAL CENTER FOR HEALTH STATISTICS
}

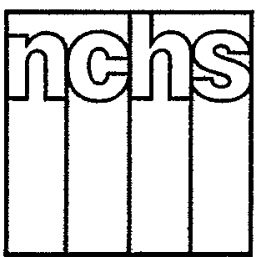

The National

Committee on

\section{Vital and Health \\ Statistics, 1988}

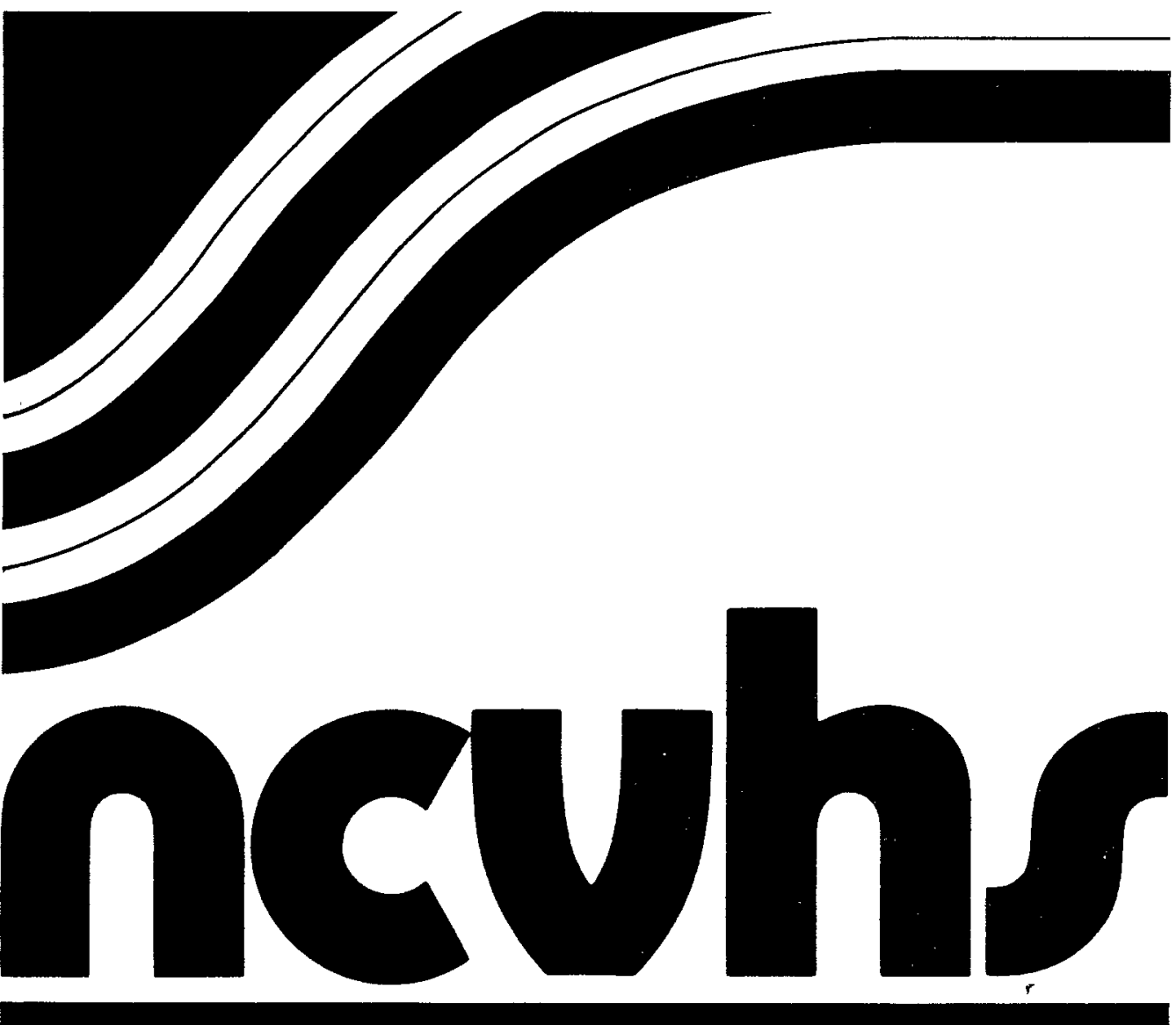

U.S. DEPARTMENT OF HEALTH AND HUMAN SERVICES Public Health Service

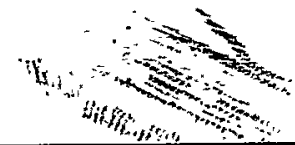
Centers for Disease Control 

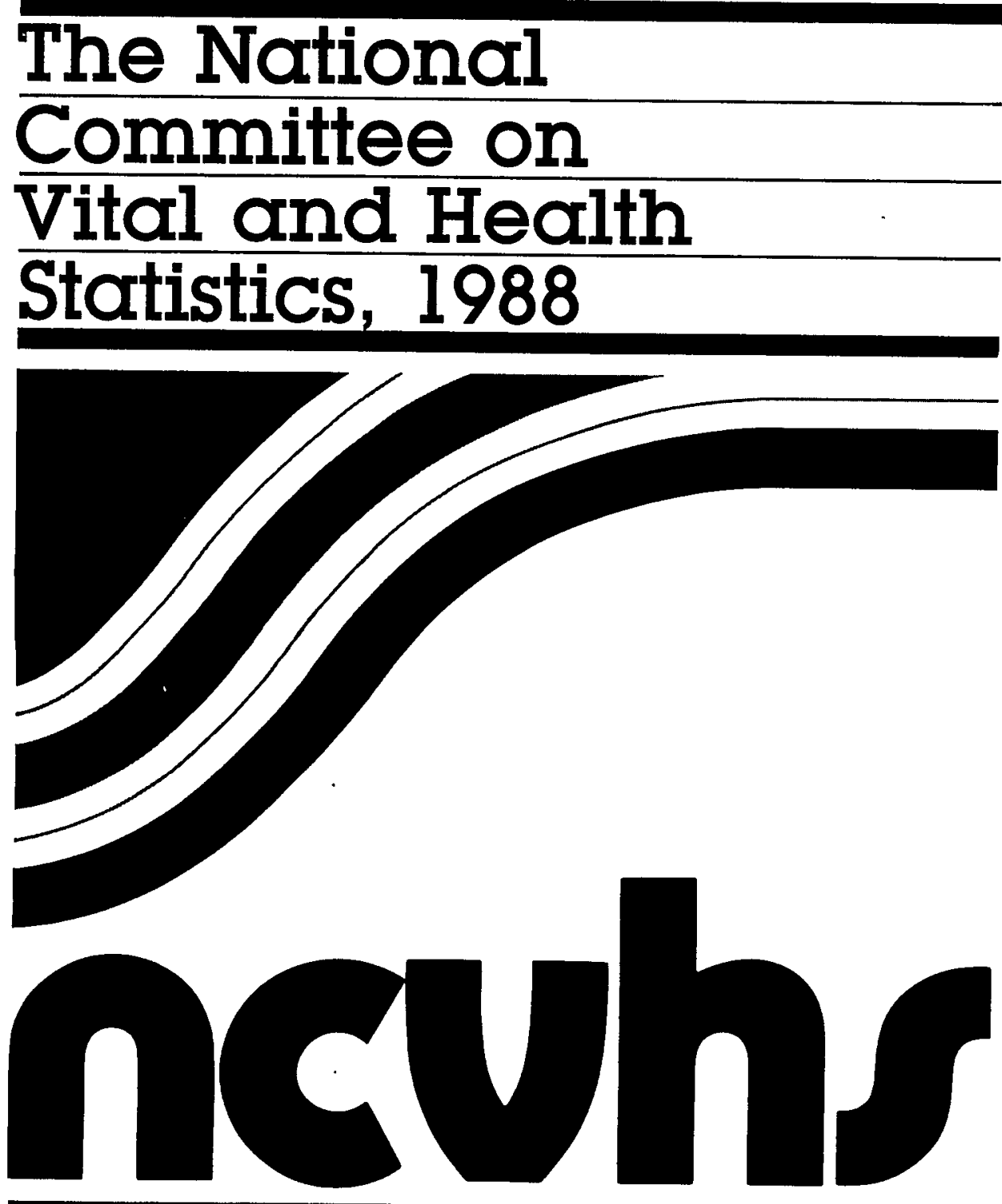

DHHS Publication No. (PHS) 89-1205

U.S. DEPARTMENT OF HEALTH AND HUMAN SERVICES

Public Health Service

Centers for Disease Control

National Center for Health Statistics

Hyattsville, Maryland

May 1989 


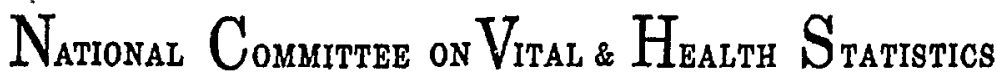

RONALD G. BLANKENGAKER, M.D. CHAIRMAN

The Honorable Otis R. Bowen, M.D.

Secretary, Department of Health

and Human Services

Washington, D.C. 20201 .

Dear Secretary Bowen:

I am pleased to transmit to you, on behalf of the National Committee on Vital and Health Statistics (NCVHS), the 1988 Annual Report as required by the Committee's Charter.

The Committee has had a very active year, highlighted by the completion of reports on long-tom care statistics, minority health statistics, and data dissemination issues. The Comittee also has continued its extensive liaison with public and private sector groups.

This Annual Report describes the Commltcee's accomplishments during 1988 and its plans to extend and expand activities in a varlety of areas during 1989. The Gomittee also looks forward to assisting the Department with other health data issues as they omerge.

Sincerely yours,

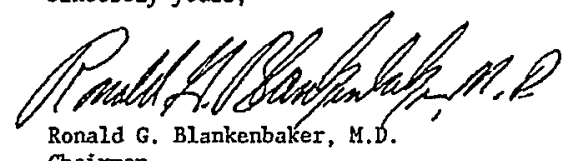
Chairman 


\section{Foreword}

This report reflects the activities of the National Committee on Vital and Health Statistics for calendar year 1988, a transition year for the Committee. During this time, the chairmen of the Subcommittee on Long-Term Care Statistics, Ambulatory Care Statistics, and Disease Prevention and Health Promotion Statistics all retired from the Committee. In addition, the Work Group on Data Dissemination Issues, which was created in 1987, successfully completed its efforts; its final report is included in appendix VII. Although the leadership of the retiring members was exemplary, we are fortunate to have an excellent membership from which new and equally effective chairmen have been selected for two of the subcommittees.

The work of all subcommittees, as described in this report, is proof of the expanding impact of the Committee as an advisory conduit between public and private statistical bodies. In 1987, the Public Health Service Act was amended to expand the Committee from 15 members, with terms of 3 years each, to 16 members, with terms of 4 years each. This change has the potential of increasing the Committee's productivity and providing for even better continuity of the Committee's activities.

Because of the reorganization at the Health Care Financing Administration (HCFA), Committee-related activities in that organization were moved from the Bureau of Data Management and Strategy to the Bureau of Eligibility, Reimbursement, and Coverage (BERC). Although we valued the very capable staffing and coordination provided through the prior relationship, we are equally pleased with the open, friendly, and cooperative efforts of the staff of BERC.

In addition to its ongoing agenda of important statistical projects and monitoring activities, the Committee became involved in the National Center for Health Statistics' (NCHS) revision and expansion of current health care surveys to improve statistical analyses and coordination among the various surveys. The new Subcommittee on Health Care Statistics was created to assist NCHS in these efforts.

This annual report is the primary mechanism through which the Committee communicates its activities to the Department of Health and Human Services and other appropriate agencies and organizations. Consequently, we have included explanations of the processes through which the full Committee and subcommittees work as well as our plans for the next several years. Additionally, we have organized this year's report in a manner that should make it easier for the reader to refer to specific issues and recommendations in each topic area.

We hope that this report will reach many of those individuals with a responsibility and interest in the collection, analysis, and dissemination of health data in the United 
States and the world. We will deem our efforts successful if the recommendations presented here stimulate other statistical activities and result in an overall improvement in the availability, quality, and accessibility of useful health data.

I would like to give special recognition to the current members of the Committee, to those who have retired over the past 3 years, and to the able staff provided by NCHS and HCFA. Their work has been outstanding, especially considering the limited resources available to them because of significant budgetary constraints. They have been untiring in their efforts, undaunted by difficult tasks, and innovative in their manner of providing useful advice to the Department. This report is a telling tribute.

Ronald G. Blankenbaker, M.D.

Chairman, National Committee on Vital and Health Statistics 


\section{Contents}

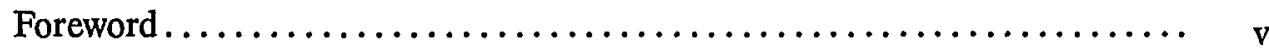

Executive Summary $\ldots \ldots \ldots \ldots \ldots \ldots \ldots \ldots \ldots \ldots \ldots \ldots \ldots \ldots \ldots \ldots \ldots \ldots, 1$

Activities, Accomplishments, and Future Plans of the National Committee on

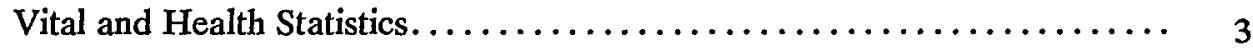

Medical Classification Systems ........................... 5

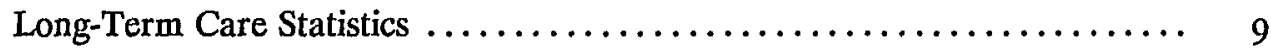

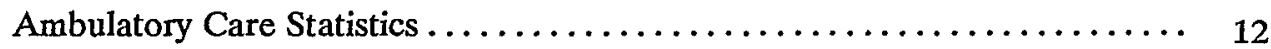

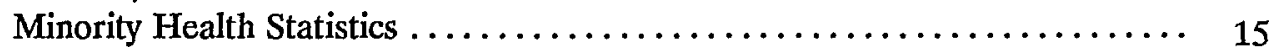

Health Care Statistics $\ldots \ldots \ldots \ldots \ldots \ldots \ldots \ldots \ldots \ldots \ldots \ldots \ldots \ldots \ldots, 18$

Data Dissemination Issues $\ldots \ldots \ldots \ldots \ldots \ldots \ldots \ldots \ldots \ldots \ldots \ldots \ldots, 20$

Appendixes

Appendix I. Legislative Authority for the National Committee on Vital and Health Statistics from the Public Health Service Act $\ldots \ldots \ldots \ldots \ldots \ldots \ldots, 22$

Appendix II. Charter $\ldots \ldots \ldots \ldots \ldots \ldots \ldots \ldots \ldots \ldots \ldots \ldots \ldots \ldots, 24$

Appendix III. Membership Roster of the National Committee on Vital and Health Statistics $\ldots \ldots \ldots \ldots \ldots \ldots \ldots \ldots \ldots \ldots \ldots \ldots \ldots \ldots \ldots \ldots, 28$

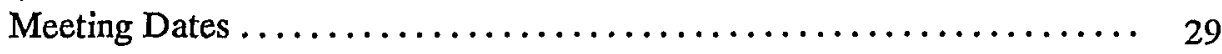

Appendix IV. Subcommittees of the National Committee on Vital and Health Statistics, Rosters, Meeting Dates, and Charges ..................

Appendix V. Report of the Subcommittee on Long-Term Care Statistics: Activities from June 1987 to June 1988

Appendix VI. Report of the Subcommittee on Minority Health Statistics.... 56

Appendix VII. Report of the Work Group on Data Dissemination Issues .... 


\section{Executive Summary}

During 1988, the National Committee on Vital and Health Statistics, in its advisory capacity to the Department of Health and Human Services (DHHS), accomplished the following activities through the work of the full Committee, seven subcommittees, and a work group:

- Submitted to the Assistant Secretary for Health a followup report on long-term care statistics, that includes recommendations on a nursing services list and functional status classification.

- Completed a report on data dissemination issues that contains recommendations supporting more systematic policies and procedures for the release of statistical information both in hard copy reports and on public use data tapes. This report also was transmitted to the Assistant Secretary for Health.

- Approved a third report for submission to the Assistant Secretary for Health, with recommendations on collecting information about the health of minorities.

- Continued to address the issues surrounding the uses of the International Classification of Diseases in the United States, soliciting public testimony on the 10th revision and endorsing the concept that there be no copyright that would impede the use of ICD-10 in this country.

- Made substantial progress in reviewing and revising the Uniform Ambulatory Medical Care Minimum Data Set (UAMCMDS), working in tandem with the DHHS Interagency Task Force on the UAMCMDS.

- Established the Subcommittee on Health Care Statistics to review the National Center for Health Statistics' (NCHS) activities in the development of the National Health Care Survey and to assist NCHS in obtaining sufficient internal and external input.

- Monitored disease prevention and health promotion statistics and related data issues on acquired immunodeficiency syndrome.

- Reviewed and provided comments on the 1988 publication of Health, United States.

- Provided comments to the Office of Management and Budget on proposed Guidelines for Federal Statistical Activities. 
- Addressed issues related to the overall adequacy of national health statistics systems and capabilities and monitored the areas of international health statistics, data on the aging population, occupational health data, and data on quality of care and patient outcomes.

- Expressed its concerns about the accuracy and validity of the causes of death reported on death certificates and initiated plans for a workshop in 1989 to obtain input on improving the reporting of these data.

In 1989, the Committee will continue and expand efforts related to many of the above activities. 


\section{Activities, Accomplishments, and Future Plans of the \\ National Committee on Vital \\ and Health Statistics}

The National Committee on Vital and Health Statistics (NCVHS) continued to encourage the development of high quality, comparable, and relevant health data throughout its activities in 1988.

In accordance with 1987 amendments to the Public Health Service Act, membership on the Committee was expanded from 15 to 16 members, and membership terms for new appointees were increased from 3 to 4 years, on a phase-in basis.

During 1988, the Committee carried out substantive work in the following selected areas through its active subcommittee structure:

- Medical classification systems

- Long-term care statistics

- Ambulatory care statistics

- Minority health statistics

- Health care statistics

A new subcommittee was created to address the last area.

The activities, accomplishments, and future plans of the subcommittees are detailed in the subsequent sections of this report. Membership lists, meeting dates, and charges for the subcommittees are included in appendix IV.

In addition, the Work Group on Data Dissemination Issues completed its responsibilities during 1988 and issued a final report. The activities and accomplishments of this work group are also described.

Following the retirement of the Subcommittee Chairman in June 1988, the Subcommittee on Disease Prevention and Health Promotion Statistics became inactive. However, the full Committee has continued to monitor this area and related data issues on acquired immunodeficiency syndrome (AIDS) and received two relevant 
presentations from the Institute of Medicine (IOM) at the November 1988 NCVHS meeting. These reports covered the IOM Workshop on Statistical Issues in the Year 2000 Health Objectives and the IOM Study on the Future of Public Health in the United States. Additional presentations and assessment of the Committee's role in disease prevention and health promotion statistics, as well as in AIDS data, are planned during 1989.

A number of additional issues are being monitored by the Executive Subcommittee, the full Committee, and individual members.

As in previous years, the Committee worked with the National Center for Health Statistics (NCHS) on the development of Health, United States, the Secretary's annual report on the health of the Nation. Through this review process, the Committee addresses the overall adequacy of national health statistical systems and capabilities. The reports on the IOM studies and a presentation received on the national mental health statistical programs also relate to this broad interest.

NCHS provides periodic briefings on international health statistics, data on the aging population, and occupational health data, all of which have been monitored by individual members of the Committee. Other topics under consideration by the different subcommittees are also regularly covered in NCHS reports. Several briefings have been received from the Health Care Financing Administration (HCFA) concerning data initiatives on quality of care and patient outcomes, another area of interest to the Committee. HCFA also has begun regularly to brief the Committee on new developments and research related to the Medicare data systems.

Regarding quality of data, the NCVHS intends to hold a workshop on improving the accuracy and validity of cause-of-death reporting on death certificates during 1989. The Committee considers this to be a very important statistical issue because the death certificate is the primary source of mortality data in the United States. Concerns have been raised about inadequate physician education in this area, a declining autopsy rate, and confidentiality issues that may lead to underreporting of certain conditions, such as AIDS.

In all of these areas, the NCVHS Executive Subcommittee has continued to assist the Chairman in coordinating and facilitating the activities of the subcommittees, work group, and individual monitors, and in assuring that work plans are developed and maintained. 


\section{Medical Classification Systems}

During 1988, the Subcommittee on Medical Classification Systems continued to address the issues surrounding the uses of the International Classification of Diseases (ICD) in the United States. The ICD has long been used to collect, analyze, and report health-related data. In addition, the ICD often serves as the infrastructure of the data sets used in the creation of effective public policy. Both the testimony received by the Subcommittee and the agenda for the working sessions centered on the following topics: the current status of the ICD-10th revision, development of coding guidelines, specialty-specific classifications, coordination and maintenance functions, and need for a single procedure coding system. The Subcommittee will continue to address these issues in the coming year.

\section{Recommendation}

- At the November meeting of the National Committee on Vital and Health Statistics (NCVHS), the Subcommittee on Medical Classification Systems recommended, and the NCVHS endorsed, the important concept that there be no copyright by the World Health Organization (WHO) that would impede the use of ICD-10 in this country.

\section{Background}

The Subcommittee on Medical Classification Systems was established in 1987 as a continuation of the Subcommittee on Disease Classification and Automated Coding of Medical Diagnoses, which had been functioning since June 1983. There has been a long commitment by the NCVHS to address the complex issues related to the ICD and its multiple uses. The newer title acknowledges the expansion of the Subcommittee's focus to medical classification systems, including, but not limited to, the scope of the ICD.

\section{Current Year's Activities}

The Subcommittee held four meetings during 1988-March 21-22, June 2, July 25-26, and November 3-and continued to pursue its charge through the solicitation and assimilation of public testimony, which became the foundation of discussion at working sessions, as described below. 


\section{Current Status of ICD-10}

Although ICD-10 continues to progress through the drafting cycle, its basic structure is well established, and a major reorganization would be precluded by the time constraints of the planned implementation process. This has not, however, prevented the addition of useful clinical detail nor the accommodation of specific rubrics and definitions at the request of the clinical community. For example, information on the place of occurrence has been added to the external cause of injury chapter to facilitate the design of accident prevention strategies. Further, the American Psychiatric Association (APA) has worked closely with WHO to achieve as great an agreement as possible between the ICD and the APA publication, the Diagnostic and Statistical Manual.

Listed among the Subcommittee's charges was the question of the need for a U.S. clinical modification of ICD-10. In an attempt to make that assessment both objective and as widely representative as possible, the Subcommittee mailed copies of the latest draft (or pertinent sections) to interested individuals and organizations. The accompanying letter requested specific suggestions on the need for more detail, the need for a potential formulation of morbidity guidelines, and an assessment of whether conversion to a single procedure classification would represent a wise use of both public and private resources.

The Subcommittee heard testimony at its March meeting on the need for a clinical modification to ICD-10, an ICD-10-CM. Testimony from the public and private sector included comments on the applicability of ICD-10 to meet multiple program needs, such as prospective payment, severity indexing, clinical specialty uses, and hospital applications. In a related effort, the American Medical Association (AMA) polled the 74 medical specialty societies to obtain their opinions on the clinical adequacy of the current draft of ICD-10. In the July working session, the Subcommittee agreed, and the AMA concurred (in a separate communication), that a modification of ICD-10 in the tradition of ICD-9-CM is not required.

Even though no recommendation was made for a modification, the Subcommittee is strongly supportive of a flexible and viable updating mechanism for the ICD. Although the need exists internationally, it is particularly critical in the United States, where the classification must satisfy multiple program requirements for both morbidity and mortality.

The Subcommittee's concern over the proposed WHO copyright of ICD-10 is shared by both the National Center for Health Statistics (NCHS) and the Health Care Financing Administration (HCFA). As a result, a letter was prepared to be sent by the Department of Health and Human Services to the Director General of WHO requesting clarification of the copyright and of any restrictions it would impose on U.S. health policy administrators, professional societies, and health institutions to use or modify ICD-10. Even though HCFA and the programs in the Public Health Service want to use ICD-10 because it represents an advancement over ICD-9-CM, if 
necessary, ICD-9-CM can continue to be modified for use in payment and quality assessment programs. After considerable deliberation, the Subcommittee formulated a strong recommendation that there be no copyright that would impede the use of ICD-10 in the United States.

\section{Development of Coding Guidelines}

Traditionally, guidelines or rules for mortality coding (underlying cause) have been created and accepted internationally, but guidelines for morbidity coding have not required international accord. As a result, there was the creation and dissemination of coding guidelines by various user groups with no central control over the approval process. More recently, through the cooperating party agreements (the American Medical Record Association, the American Hospital Association, the National Center for Health Statistics, and the Health Care Financing Administration) official guidelines have been created, approved, and disseminated. Although the Subcommittee agrees that guidelines should be application neutral, it has emphasized that the development of guidelines, like the modification to the classification, needs to be representative of a widely participative process.

\section{Specialty-Specific Classification}

There has been a recent trend among physician specialty groups to create classifications that will be of use to their practitioners in reimbursement monitoring or research programs. Typically, these classifications contain additional detail beyond the core ICD code. As the appeal for specialty classifications becomes more widespread, the potential for specialties competing over extensions to codes increases. The Subcommittee identified the need for control of code assignment and clearly saw the need for an identified group or agency that would provide some credibility to that process.

\section{Coordination and Maintenance Committee}

The Subcommittee reviewed the history, current structure, and function of the Coordination and Maintenance Committee as an interagency committee advisory to the Administrator of HCFA and the Director of NCHS. Organized in 1985, the Coordination and Maintenance Committee was the result of the recognition that a mechanism to review and update the classification was required.

As an interagency committee, its current focus, both Federal sector membership and private sector invited participants, depicts institutional dominance. Although the historic reasons for this are apparent, the greater portion of morbidity data in the next decade will be generated from sectors other than acute-care hospitals. The Subcommittee strongly supports the continuing need for a coordination and maintenance function, but with a more representational balance in membership. 


\section{Procedure Classification}

The Subcommittee also addressed the issue of whether the two procedure coding systems, ICD-9-CM or Physicians' Current Procedural Terminology, Fourth Edition (CPT-4), should be replaced by a single system as recommended by the predecessor subcommittee. Earlier review efforts found structural problems in both ICD-9-CM and CPT-4; and, although the cost of submitting data in more than one classification is not minimal, concern for data quality issues are even more significant. Moreover, the two systems use different dates for implementing changes.

Even though conversion to a single procedure coding system has inherent appeal, it is difficult to advocate converting to a system without knowing if it will adequately serve institutional internal needs and be satisfactory for use in the payment system for providers (physicians and institutions). The feasibility of developing a single procedure coding system that will satisfy the interested physicians, other health care practitioners, hospitals, and payors, is as yet unknown. In an effort to provide some reliable data to respond to the question of feasibility and utility, the AMA has released a request for proposal to investigate the cost and benefits of a single system. It is anticipated that the results of this study will be the subject of subsequent testimony to the Subcommittee. The Subcommittee delayed an additional discussion of the procedure code in anticipation of this testimony.

\section{Continuing Work Plan}

The Subcommittee intends to carry out the following work plan in 1989:

- Continue to monitor the progress of ICD-10 and participate in the formulation of any U.S. recommendations to WHO.

- Assess the benefits and costs of converting to a single procedure coding system in the United States.

- Review and recommend the structure and process necessary for the formation of a public and private sector coalition to implement and maintain a classification in the United States (Secretariat function).

- Provide liaison to the ICD-9-CM Coordination and Maintenance Committee to ensure the utility and integrity of ICD-9-CM in its broadly based, multiuse applications throughout the United States.

- Address other medical classification systems as the need arises. Specifically, a working group of the Subcommittee has been established to consider the application of ICD-9-CM to diagnoses in nursing homes or other long-term care settings.

The Subcommittee continues to appreciate its role as a forum on the revision issues for the International Classification of Diseases. Providing guidance to the U.S. input to the draft and to the entire revision process is a unique opportunity. 


\section{Long-Term C Care Statistics}

During 1988, the Subcommittee on Long-Term Care Statistics submitted a followup report to the National Committee on Vital and Health Statistics (NCVHS), which included rationale and recommendations in two related areas: a nursing services list and functional status classification. The report was approved by the NCVHS at its June 1988 meeting and transmitted to the Assistant Secretary for Health. Subsequently, the Subcommittee (with four new members) considered the availability of statistics on board and care homes, initiated review of a new Health Care Financing Administration (HCFA) nursing home resident assessment instrument, and began to consider quality-of-life measures and interrelationships of health statistics with mental health statistics. In the coming year, the Subcommittee will develop recommendations in these and related areas.

\section{Recommendations}

The 1988 report of the Subcommittee on Long-Term Care Statistics (LTCS) can be found in appendix $\mathrm{V}$ and includes the following findings and recommendations:

- The Subcommittee addressed expansion of the information on nursing services in the Long-Term Care Minimum Data Set (LTCMDS). In its original form the minimum data set included only the provision for a "yes or no" response for receipt of nursing services. As an immediate improvement, the Subcommittee recommended incorporation into the LTCMDS of an expanded nursing service list as developed by the HCFA. With the assistance of the American Nurses Association, the Subcommittee attempted to develop a more inclusive nursing service list. However, a much more extensive public-private effort would be necessary to complete this list.

- The Subcommittee considers the measurement of functional status of clients an important aspect of long-term care data. Additionally, a common set of questions called the "activities of daily living" has been used. However, there are several issues that need to be addressed to improve the validity and reliability of functional status measures. The Subcommittee concluded that resolving these issues will necessitate a broad-based effort by researchers and users of such information. Such an undertaking would necessitate special departmental support beyond what could be provided by the NCVHS. 


\section{Background}

The NCVHS originally was charged to review the LTCMDS in 1983 by the departmental Health Information Policy Council. This review was carried out from 1984 to 1987 by the Subcommittee on Uniform Minimum Health Data Sets. The 3-year effort produced a report (in June 1987) to the Assistant Secretary for Health with the recommendation for a LTCMDS to be used with nursing home residents. This strategy resulted from the inability of the Subcommittee to develop a comprehensive instrument that would be satisfactory for use with individuals in all the various locations where long-term care is delivered. Following submission of its report, the Subcommittee was reconstituted as the Subcommittee on Long-Term Care Statistics, with a charge related specifically to the adequacy of information on long-term care policy issues.

\section{Current Year's Activities}

During 1988, the Subcommittee on LTCS heard testimony on possible study strategies for assessing information about board and care clients. There is a current lack of statistics on those receiving such care. The Subcommittee is awaiting protocol development by the Office of the Assistant Secretary for Planning and Evaluation in the Department of Health and Human Services, as well as a report from the General Accounting Office, before pursuing this topic further.

The 1987 Omnibus Budget Reconciliation Act requires the Secretary of Health and Human Services to propose a uniform resident assessment instrument to be completed for every resident of nursing homes at specific intervals. This new requirement might provide an opportunity to monitor quality of care and quality of life and perhaps to indicate ways to restructure the financing of institutional long-term care. The Subcommittee on LTCS anticipates monitoring the development of a Resident Assessment Instrument, which will be proposed and refined by the HCFA during 1989 and 1990.

The Subcommittee specifically addressed the quality-of-life issue in nursing homes by inviting experts from Federal and State governments, as well as the private sector, to suggest strategies for measuring quality of life in nursing home residents. At present, there is no agreed on construct or set of questions to be recommended. The Subcommittee will develop this area further.

There are overlaps between the collection of general health statistics and mental health statistics in the context of long-term care delivery. The Subcommittee will explore opportunities for integrating such data. In the nursing home setting, mental problems, including cognitive deficits, interact with physical problems resulting in the 
need for continued institutionalization. On a broader basis, national data systems might be adapted to provide better information.

A member of the Subcommittee had been monitoring the area of data on the aging population for the full Committee. After his retirement from the NCVHS, this monitoring function was assumed by the Subcommittee.

\section{Continuing Work Plan}

As indicated above, the Subcommittee intends to carry out the following work plan in 1989:

- Review the reports of the Interagency Task Force on the Long-Term Care Facility Minimum Data Set and the Interagency Task Force on the Long-Term Care Client Minimum Data Set.

- Monitor consideration of recommendations contained in the National Research Council study, The Aging Population in the Twenty-First Century, and general aging issues.

- Monitor the development and review the Secretary's recommendation for a resident assessment instrument for nursing homes.

- Review recommendations for a proposed survey of board and care homes.

- Initiate a review of quality-of-life assessment strategies in long-term care facilities.

- Examine possible linkage of long-term care to mental health data bases.

- Encourage better descriptions of the availability and utilization of nursing home beds for long-term care and their variation in the country. 


\section{Ambulatory Care Statistics}

The Subcommittee on Ambulatory Care Statistics made substantial progress during 1988 in carrying out its charge to review and revise the Uniform Ambulatory Medical Care Minimum Data Set (UAMCMDS). The Subcommittee presented an interim report on the data set to the National Committee on Vital and Health Statistics (NCVHS) at the Committee's June meeting and, based on comments and subsequent discussion, provided a revision of this report at the November NCVHS meeting. Throughout these activities, the Subcommittee has worked closely with the Interagency Task Force on the Uniform Ambulatory Medical Care Minimum Data Set, which is chaired by the Health Care Financing Administration. The Subcommittee and Task Force both intend to complete their parallel reviews and recommend a revised data set by the June 1989 NCVHS meeting.

\section{Recommendations}

As currently configured, the revised Uniform Ambulatory Medical Care Data Set will have the following characteristics:

- The list of items will be reasonably consistent with the data set recommended by the NCVHS to the Secretary of the Department of Health and Human Services in 1980 and published by the Department in 1981, with delineation of items that characterize the patient, the provider, and the encounter. Although widely disseminated, this data set has not been officially acted on by the Department.

- The Subcommittee and the Interagency Task Force on the UAMCMDS have recommended eliminating the term "minimum" from the title of the data set and focusing instead on developing uniform definitions for the core set of data items that are most likely to be needed by a variety of users.

- In the revision, attempts will be made to build bridges between the core data set and both reimbursement applications and quality and effectiveness of care applications.

- The revision will include recommendations on those items that should be abstracted uniformly from medical records into ambulatory care data bases. 
- The ability to link records is considered an essential aspect of the data set.

- Appropriate safeguards must be established for protecting the confidentiality of identifiable data collected.

\section{Background}

The Subcommittee on Ambulatory Care Statistics was formed at the June 1987 NCVHS meeting as a direct outgrowth of the work of the Subcommittee on Statistical Aspects of Physician Payment Systems. The latter began as a work group in 1984, with the concurrence of the Assistant Secretary for Health, and had recommended in its final report that a thorough and systematic review of all items in the UAMCMDS be undertaken by the NCVHS and the Department. The Subcommittee on Ambulatory Care Statistics was created specifically to respond to this recommendation and to provide liaison with the Interagency Task Force, which was established by the Assistant Secretary for Health in the spring of 1987 to carry out the departmental review of the UAMCMDS.

\section{Current year's activities}

The Subcommittee met on January 11-12, 1988, to discuss the UAMCMDS with public and private sector representatives and to receive updates from HCFA on ambulatory care research and demonstration projects. The Subcommittee had sent a letter to approximately 70 individuals and organizations outside of the Department, inviting them to comment on the current UAMCMDS and to provide testimony at the January meeting. Several of the presentations were responsive to previous gaps in the Subcommittee's information gathering on the perspectives of the research community and State data collection. The Subcommittee subsequently held a working session on February 3,1988, with representatives of the Group Health Association of America to discuss health maintenance organization data capabilities and needs.

Additional Subcommittee meetings were held on April 26-27, August 15-16, and October 3,1988, specifically to review the items in the UAMCMDS in conjunction with selected members of the Interagency Task Force. The Subcommittee Chairman and staff also attended bimonthly meetings of the Interagency Task Force to assure adequate liaison between the two groups.

In the interest of completing its review of the data set by the scheduled time, the Subcommittee has focussed its monitoring of the statistical aspects of physician payment systems on issues directly related to the data set. For example, the Medicare Catastrophic Coverage Act of 1988 requires that physicians code diagnostic information on all bills submitted for services furnished after March 31, 1989. The Subcom- 
mittee has reviewed the diagnostic coding guidelines approved by HCFA for hospital outpatient services to assess their applicability for physician reporting in all settings necessitated by the statute. Other statistical issues under consideration involve implementation of the drug benefit in the Catastrophic Coverage legislation and relative value scale research.

\section{Continuing work plan}

The Subcommittee intends to carry out the following work plan in 1989:

- Complete the review of the Uniform Ambulatory Medical Care Minimum Data Set and recommend to the NCVHS a revised data set.

- Continue to serve as liaison to the departmental Interagency Task Force on the UAMCMDS.

- Monitor the statistical aspects of physician payment systems as they relate directly to the UAMCMDC. 


\section{Minority Health Statistics}

The Subcommittee on Minority Health Statistics devoted considerable attention during 1988 to the adequacy of racial and ethnic identifiers in the Medicare data systems. In addition, the Subcommittee held a public hearing on May 10, 1988, to receive testimony on the unmet statistical data needs for research and policy formation on minority populations. A report of the hearing, with recommendations, was presented to the National Committee on Vital and Health Statistics (NCVHS) at the November 1988 meeting, and approved for transmittal to the Assistant Secretary for Health. The Subcommittee will pursue these issues and will address health data on the medically indigent in the coming year.

\section{Recommendations}

The report of the Subcommittee on Minority Health Statistics, which was presented at the November NCVHS meeting and can be found in appendix VI, contains the following recommendations:

- To provide the capability for policy analysis and research on health issues related to minority populations, all person-based health data systems supported or maintained by the Department of Health and Human Services should make possible racial and ethnic identification in a uniform fashion.

- To promote adequate precision of health statistics on minority populations, the Secretary should:

- Continue to support the practice of oversampling minorities in national surveys when appropriate.

- Periodically review the status of newly planned national surveys of health data to ensure that all considerations are being made to provide adequate sample sizes for minority populations.

\section{Background}

The Subcommittee on Minority Health Statistics was established by the NCVHS in 1986 after the Secretary's Task Force on Black and Minority Health noted that there was a need for data on minority populations and identified a need to improve and fully utilize available sources of data. 


\section{Current Year's Activities}

On May 10, 1988, the Subcommittee held a hearing that was attended by representatives of both the public and private sectors. The presenters reinforced the value of uniform coding of racial and ethnic identifiers in health data and health records collected by the Federal Government and the private sector. Most presenters discussed the limitations of sample size of many national surveys precluding reliable analyses of certain racial and ethnic groups and the tremendous potential use of Medicare and Medicaid data.

In February 1988, the National Committee, at the request of the Subcommittee, had recommended to the Assistant Secretary for Health that the Health Care Financing Administration (HCFA) consider obtaining racial and ethnic information on Medicare claims forms which were under revision. HCFA responded that collecting these data on a billing form would be costly and unreliable because of the volume of input, the reconciliation of conflicting data, the expense of initial data development, and the data maintenance and retention issues.

Although the members of the Subcommittee subsequently agreed that the Medicare claims forms may not be the most appropriate tool for the collection of race and ethnicity, they believe that other alternatives must be considered. The Subcommittee will continue to pursue this issue with HCFA in 1989 because the need for racial and ethnic data warrants the exploration of every avenue.

\section{Continuing Work Plan}

Specifically, the Subcommittee will focus on six areas of activity during 1989.

- Pursue with HCFA and the Social Security Administration the racial and ethnic identifiers in the data systems of Medicare and Medicaid.

- Begin to address health data issues specifically with respect to the medically indigent and to conduct public hearings as one of the first steps to help generate consensus.

- Work with the Office of Minority Health in the formulation of minority health data development and in the implementation of their work plan.

- Identify surveys, forms, and other data collection efforts of the Department of Health and Human Services (DHHS) that are in the planning stages for the purpose of determining the ability of these data systems to produce data on minorities. 
- Review mechanisms that DHHS uses as outreach and data dissemination on minority health.

- Monitor health data activities to enhance training in and encourage the appropriate use and analysis of health data on minorities. 


\section{Health Care Statistics}

The Subcommittee on Health Care Statistics was organized at the June 1988 meeting of the full National Committee on Vital and Health Statistics (NCVHS) to review the National Center for Health Statistics (NCHS) activities in the development of the National Health Care Survey. The Subcommittee's purpose is to assist NCHS in obtaining sufficient internal and external input to the development of the survey and the related policy implications. The Subcommittee will focus on the areas of coverage, implementation priorities, and comparability among minimum data sets, especially as they impact on the National Health Care Survey.

\section{Background}

In recent years, there have been profound changes in the organization, financing, and delivery of health care, brought about, in part, by cost-containment initiatives, competition, aging of the population, and changes in the practice of medicine. These changes have outpaced the capabilities of existing data systems to provide relevant and timely data. Therefore, NCHS has developed a plan to restructure and integrate its individual surveys of health care facilities and providers into an integrated system, the National Health Care Survey. Because these changes have major implications for the future availability of health care information, the NCVHS established a Subcommittee to monitor this system.

\section{Current Year's Activities}

During 1988, the Subcommittee held two meetings, one on September 15 and the other on December 15. The primary purposes of the first meeting were to review plans developed by NCHS to redesign and expand its surveys of health care providers and to discuss the role and directions of the Subcommittee.

The second meeting was a working session of the Subcommittee to review NCHS implementation plans, to discuss other advisory mechanisms for the survey, and to examine the comparability of minimum data sets that may be used in components of the National Health Care Survey. 


\section{Continuing Work Plan}

During 1989, the Subcommittee will carry out the following work plan:

- Continue to monitor NCHS activities to develop the National Health Care Survey program.

- Assure that adequate mechanisms are established for NCHS to obtain broadbased input from the health and statistical community as plans are developed.

- Assume more of a lead in areas of special interest to the NCVHS, such as minimum data sets and their use in NCHS provider surveys. 


\section{Data Dissemination Issues}

During the past year the Work Group on Data Dissemination Issues completed its investigation into questions related to the release of data by the Department of Health and Human Services (DHHS) agencies and prepared a report with recommendations. The report was endorsed by the full National Committee on Vital and Health Statistics (NCVHS) and transmitted to the Assistant Secretary for Health in July 1988. The Work Group also assisted the Executive Subcommittee in the preparation of comments on the Office of Management and Budget's proposed Guidelines for Federal Statistical Activities. The Group was disbanded at the June 1988 meeting of the full Committee.

\section{Recommendations}

The final report of the Work Group on Data Dissemination Issues, which is presented in Appendix VII, contains the following recommendations:

- The Work Group recommends that voluntary data releases be accompanied by full documentation of study methodologies. Information on data imputation and use of proxy responses should be part of the documentation. Data released in response to a Freedom of Information act request should, as a minimum, be accompanied by all pertinent caveats and disclaimers.

- The Work Group supports the dissemination of data through public use data tapes and urges agencies to develop positive policies towards dissemination of data in this form. The Group's recognition of the importance of disseminating information through public use tapes is tempered by an appreciation of the problems facing DHHS agencies. This consideration is reflected in the NCVHS letter to the Office of Management and Budget of April 12, 1988. To quote from that document "... we support the concept of immediate availability of public use data tapes ... However, we believe there should be an opportunity for negotiation on appropriate timing in light of available resources and the need to publish findings quickly."

- Diagnostic data are an important component of several major Federal data systems. In response to concerns about the quality of these data, the Work Group 
recommended, and the full committee concurred, that the NCVHS Subcommittee on Medical Classification Systems should address issues related to the accuracy of the diagnostic information obtained and coded according to ICD-9-CM.

- The Committee on National Statistics of the National Academy of Sciences is addressing topics in the area of data access. The Work Group recommends that the NCVHS establish an ongoing liaison with this committee.

\section{Background}

The Work Group on Data Dissemination Issues was created by the NCVHS in June 1987 and charged with preparing a "white paper" on issues associated with the quality of data released by DHHS agencies, making recommendations for addressing these issues and suggesting ways in which the committee could move more broadly into the data dissemination area.

\section{Current Year's Activities}

The Work Group had held its first working meeting on October 7-8, 1987, and held a second working session on March 29, 1988. The latter followed a public hearing on March 28, 1988, to collect information about agency practices in the dissemination of data through public use tapes. Eight DHHS agencies made presentations at the public hearing. Although the Work Group was dissolved after completing its charge, the NCVHS Executive Subcommittee is monitoring the Department's responses to the Work Group report. The recommendation addressed to the full committee, concerning liaison between the NCVHS and the Committee on National Statistics, already has been acted on, with presentations exchanged by the two organizations. 


\section{Appendix I. Legislative Authority for the National Committee on Vital and Health Statistics From the Public Health Service Act}

\section{Section 306 subsection (k) of Public Health Service Act}

(1) There is established in the Office of the Secretary a committee to be known as the National Committee on Vital and Health Statistics (hereinafter in this subsection, referred to as the "Committee") which shall consist of sixteen members.

(2) (A) The members of the Committee shall be appointed by the Secretary from among persons who have distinguished themselves in the fields of health statistics, health planning, epidemiology, and the provision of health services. Except as provided in subparagraph (B), members of the Committee shall be appointed for terms of four years.

(B) (i) In the case of membership terms on the Committee under this subsection (as in effect prior to January 1,1988), which expire in calendar year 1988, the appointments to three such terms in such calendar year shall be for a period of four years and the appointments to two such terms in such calendar year shall be for a period of three years, as designated by the Secretary.

(ii) In the case of membership terms on the Committee under this subsection (as in effect prior to January 1, 1988), which expire in calendar year 1989, one such term shall be extended for an additional consecutive one-year period, as designated by the Secretary.

(iii) In the case of membership terms on the Committee under this subsection (as in effect prior to January 1,1988), which expire in calendar year 1990, two of such terms shall each be extended for an additional consecutive one-year period, as designated by the Secretary.

(3) Members of the Committee shall be compensated in accordance with section 208(c).

(4) It shall be the function of the Committee to assist and advise the Secretary-

(A) to delineate statistical problems bearing on health and health services which are of national or international interest;

(B) to stimulate studies of such problems by other organizations and agencies whenever possible or to make investigations of such problems through subcommittees;

(C) to determine, approve, and revise the terms, definitions, classifications, and guidelines for assessing health status and health services, their distribution, and costs, for use (i) within the Department of Health and Human Services, (ii) by all programs administered or funded by the Secretary, including the Federal-State-local cooperative health statistics system referred to in subsection (e), and (iii) to the extent possible as determined by the head of the agency involved, by the Veterans' Administration, the Department of Defense, and other Federal agencies concerned with health and health services; 
(D) with respect to the design of and approval of health statistical and health information systems concerned with the collection, processing, and tabulation of health statistics within the Department of Health and Human Services, with respect to the Cooperative Health Statistics System established under subsection (e), and with respect to the standardized means for the collection of health information and statistics to be established by the Secretary under subsection (j)(i);

(E) to review and comment on findings and proposals developed by other organizations and agencies and to make recommendations for their adoption or implementation by local, State, national, or international agencies;

(F) to cooperate with national committees of other countries and with the World Health Organization and other national agencies in the studies of problems of mutual interest; and

(G) to issue an annual report on the state of the Nation's health, its health services, their costs and distributions, and to make proposals for improvement of the Nation's health statistics and health information systems.

(5) In carrying out health statistical activities under this part, the Secretary shall consult with, and seek the advice of, the Committee and other appropriate professional advisory groups. 


\section{Appendix II. Charter}

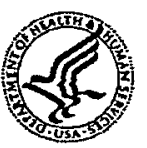

THE SECRETARY OF HEALTH AND HUMAN SERVICES

WASHING TON, D.C. 20201

CHARTER

NATIONAL COMMITTEE ON VITAL AND HEALTH STATISTICS

PURPOSE

The Secretary is charged under Section 306(k) of the Public Health Service Act, as amiended, 42 U.S.C. $242 k(k)$, with the responsibility to collect, analyze and disseminate national statistics on vital events; the extent and nature of illness and disability of the population of the United States; the impact of illness and disability of the population on the economy of the United States, and on other aspects of the well-being of its population; environnental, social, and other health hazards; determinants of health; health resources and the supply of services by health institutions; utilization of health care; health care costs and financing; family formation, growth, and dissolution; to undertake research, demonstrations, and evaluations respecting new or improved methods for obtaining current data on the matters referred to above; to undertake epidemiological research, demonstrations, and evaluations on such matters; to provide selected technical assistance to State and local jurisdictions; to coordinate health statistical and epidemiological activities of the Department; and to engage in cooperative endeavors with other countries to foster research consultation and training programs in statistical activities.

This Committee shall provide advice, consultation, and assistance and make recommendations to the Secretary through the Assistant Secretary for Health on policies and plans in developing major national systems of health data collection in the Department, on coordination of Federal health data requirements, and on analysis over a wide range of questions relating to general health problems of the population, health care resources, the use of health care services and health care financing and expenditures. In these matters, the Committee shall consult with the Health Care Financing Administration (HCFA) and other components of the Department, other Federal entities and non-Federal organizations as appropriate.

\section{AUTHORITY}

Section $306(k)$ of the Public Health Service Act, as amended, 42 U.S.C. $242 k(k)$. The Comittee is governed by provisions of Public Law 92-463 which sets forth standards for the formation and use of advisory comittees.

\section{FUNCTION}

It shall be the function of the Comittee to assist and advise the Secretary:

(A) to delineate statistical problems bearing on health and health services which are of national or international interest; 
(B) to stimulate studies of such problems by other organizations and agencies whenever possible or to make investigations of such problems through subcommittees;

(C) to determine, approve and revise the terms, definitions, classifications, and guidelines for assessing heal th status and heal th services, their distribution and costs, for use: (i) within the Department of Heal th and Human Services; (ii) by all programs administered or funded by the Secretary; and (iii) to the extent possible as determined by the head of the agency involved, by the Veterans Administration, the Department of Defense, and other Federal agencies concerned with heal th and heal th services;

(D) with respect to the design of and approval of health statistical and heal th information systems concerned with collection, processing, and tabulation of heal th statistics within the Department of Health and Human Services, and with respect to the standardized means for the collection of heal th information and statistics to be established by the Secretary under subsection (J) (1);

(E) to review and comment on findings and proposals developed by other organizations and agencies and to make recommendations for their adoption or implementation by local, State, national, or international agencies;

(F) to cooperate with national comittees of other countries and with the Horld Health Organization and other national agencies in the studies of problems of mutual interest;

(G) in the development of a report on the state of the Nation's health, its heal th services, their costs and distributions, to make proposals for improvement of the Nation's heal th statistics and health information systems, at such intervals as may be required by the Congress;

(H) in establishing standards to assure the quality of health statistical and epidemiologica1 data collection, processing, and analysis; and

(I) with respect to data on the effects of the environment on health.

\section{STRUCTURE}

The Committee shall consist of 16 members, including the Chairperson. The members of the Committee shall be appointed by the Secretary, or designee, from among persons who have distinguished themselves in the fields of heal th statistics, health planning, epidemiology, and the provision of health services. The Secretary, or designee, shall appoint the Chair for a one-year period, renewable at the discretion of the Secretary or designee.

Members shall be invited to serve for overlapping four-year terms. Terms of more than two years are contingent upon the renewal of the Committee by appropriate action prior to its termination. Any member appointed to fill a vacancy occurring prior to the expiration of the term for which his/her 
predecessor was appointed shall be appointed only for the remainder of such term. A member may serve after the expiration of his/her term until his/her successor has been appointed.

Subcommittees composed of members of the parent Cormittee may be established to provide the Committee with background study and proposals for consideration and action. The Chair shall appoint members from the parent Committee to the subcomittees and designate a Chair for each subcormittee. The Chair shall appoint ad hoc subcomittees, composed solely of members of the parent Comnittee, as necessary to address specific issues for consideration. The subcommittees shall make their recormendations to the parent Committee. Timely notification of the subcormittees and ad hoc subcommittees, inciuding charges and membership, shall be made in writing to the Department Committee Management officer by the Executive Secretary of the Cormittee.

Management and support services shall be provided by the National Center for Heal th Statistics, Centers for Disease Control.

\section{MEETINGS}

Meetings shall be held at the call of the Chair, but not less than annually, with the advance approval of a Government official who shall also approve the agenda. A Government official shall be present at all meetings.

Meetings of the subcomittees shall be held, as necessary, at the call of the respective Chair, with the advance approval of a Government official who shail also approve the agenda. A Government official shall be present at all subcominittee meetings. All subcomittees shall report their findings to the Committee.

Meetings shall be open to the public excrpt as determined otherwise by the Secretary; notice of all meetings shall be given to the public.

Meetings shall be conducted, and records of the proceedings kept, as required by the applicable laws and departmental regulations.

\section{COMPENSATION}

Members who are not full-time Federal employees shall be paid at the rate of $\$ 188$ per day, plus per diem and travel expenses in accordance with the Standard Government Travel Regulations.

ANNUAL COST ESTIMATE

Estimated annual cost for operating the Cormittee and Subcommittees, including compensation and travel expenses for members but excluding staff support, is $\$ 93,024$. Estimated annual man-years of staff support required is 2.5 , at an estimated annual cost of $\$ 102,478$. 


\section{REPORTS}

An annual report shall be submitted to the Secretary through the Assistant Secretary for Health, not later than January 31 of each year, which shall contain as a minimum a list of members and their business addresses, the Committee's functions, dates and places of meetings, and a surmary of Committee activities and recommendations made during the fiscal year. A copy of the report shall be provided to the Department Conmittee Management officer.

\section{TERMINATION DATE}

The duration of the National Committee on Vital and Health Statistics is continuing, and a new charter shall be filed no later than July 23, 1990, the date of the expiration of the next two-year period following the date of the statute estab7ishing this advisory committee, in accordance with Section $14(b)(2)$ of Public Law 92-463.

APPROVED
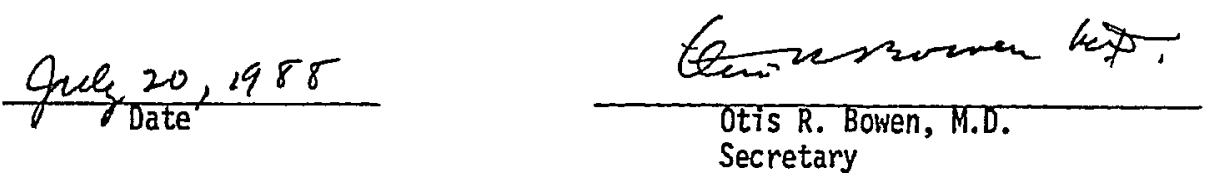


\section{Appendix III. Membership Roster of the National Committee on Vital and Health Statistics}

\section{Department of Health and Human Services \\ Office of the Assistant Secretary for Health}

\section{Chairman}

Ronald G. Blankenbaker, M.D. (1990)

Vice President for Medical Affairs

St. Vincent Hospital and

Health Care Center

2001 West 86th Street

Indianapolis, Indiana 46260

\section{Ex Officio}

Manning Feinleib, M.D., Dr.P.H.

Director, National Center for

Health Statistics

3700 East-West Highway

Hyattsville, Maryland 20782

\section{Executive Secretary}

Gail F. Fisher, Ph.D.

Associate Director, Office of Planning and Extramural Programs

National Center for Health Statistics

3700 East-West Highway

Hyattsville, Maryland 20782

\section{Current Membership}

\section{(Date Appointment Expires)}

Laurence G. Branch, Ph.D. (1992)

Professor of Public Health

Boston University Gerontology Center

67 Bay State Road

Boston, Massachusetts 02215
Frederick A. Connell, M.D. (1992)

Acting Director

Maternal and Child Health Program

School of Public Health and

Community Medicine

University of Washington, SC-37

Seattle, Washington 98195

Jane L. Delgado, Ph.D. (1990)

President and Chief Executive Officer

National Coalition of Hispanic Health and Human Services Organizations 1030 15th Street, NW, Suite 1053

Washington, D.C. 20005

William R. Felts, Jr., M.D. (1991)

Professor of Medicine

George Washington University Medical Center

2150 Pennsylvania Avenue, NW

Washington, D.C. 20037

Mary Anne Freedman (1989)

Director

Division of Public Health Statistics

Vermont Department of Health

P.O. Box 70

Burlington, Vermont 05402

Stephen F. Gibbens (1990)

730 Arcady Road

Montecito, California 93108

James K. Hutchison (1989)

Chief Actuary

The Blue Cross and Blue Shield

Association

676 North St. Clair Street

Chicago, Illinois 60611 
Judith Miller Jones (1992)

Director

The National Health Policy Forum

2011 I Street, NW, Suite 200

Washington, D.C. 20006

William H. Kirby, Jr., M.D. (1989)

Principal

Health Management Services, Inc.

401 Walpole Court

Timonium, Maryland 21093

Risa J. Lavizzo-Mourey, M.D. (1989)

Acting Director

Program in Geriatric Medicine

University of Pennsylvania

Ralston-Penn Center

3615 Chestnut Street

Philadelphia, Pennsylvania 19104-2683

Joseph R. Martin (1990)

Director

Policy Evaluation, Economics

and Health Data

American Hospital Association

840 North Lake Shore Drive

Chicago, Illinois 60611

David Mechanic, Ph.D. (1992)

Institute for Health, Health Care Policy, and Aging Research

Rutgers University

30 College Avenue

New Brunswick, New Jersey 08903

Robert L. Mullin, M.D. (1990)

Director of Continuing Care

Hospital of Saint Raphael

1450 Chapel Street

New Haven, Connecticut 06511

Bruce Steinwald (1991)

Deputy Director

Prospective Payment Assessment

Commission

300 7th Street, SW,

Suite 301-B

Washington, D.C. 20024
Karel M.'Weigel, R.R.A. (1989)

Division of Administrative Services

Mayo Clinic

200 S.W. First Street

Rochester, Minnesota 55905

Members Retired During 1988

Carmault B. Jackson, Jr., M.D.

Medical Advisory Services

16902 Hidden Timber Wood

San Antonio, Texas 78248

George C. Myers, Ph.D.

Director

Center for Demographic Studies

Duke University

2117 Campus Drive

Durham, North Carolina 27706

Lloyd F. Novick, M.D., M.P.H.

Director

Center for Community Health

New York State Health Department

Governor Nelson Rockefeller Empire

State Plaza

Corning Tower Building, Room 503

Albany, New York 12237

William J. Scanlon, Ph.D.

Co-Director

Center for Health Policy Studies

2233 Wisconsin Avenue

Washington, D.C. 20007

Gail R. Wilensky, Ph.D.

Vice President

Domestic Division

Project HOPE

Two Wisconsin Circle

Suite 500

Chevy Chase, Maryland 20815

\section{Meeting Dates}

All meetings held in Washington, D.C.

February 3-5, 1988

June 1-3, 1988

November 2-4, 1988 


\section{Appendix IV. Subcommittees of the \\ National Committee on Vital and \\ Health Statistics}

\section{Executive Subcommittee}

\section{Current Roster}

\section{Chairman}

Ronald G. Blankenbaker, M.D., Vice President for Medical Affairs

St. Vincent Hospital and Health Care Center 2001 West 86th Street

Indianapolis, Indiana 46260

Mary Anne Freedman

Director

Division of Public Health Statistics

Vermont Department of Health

P.O. Box 70

Burlington, Vermont 05402

Judith Miller Jones

Director

The National Health Policy Forum

2011 I Street, NW, Suite 200

Washington, D.C. 20006

Joseph R. Martin

Director

Policy Evaluation, Economics, and

Health Data

American Hospital Association

840 North Lake Shore Drive

Chicago, Illinois 60611
Ex Officio

Gail F. Fisher, Ph.D.

Executive Secretary

National Committee on Vital and

Health Statistics

3700 East West Highway

Hyattsville, MD 20782

Staff

Jack Anderson, NCHS

Marjorie S. Greenberg, NCHS

Thomas S. Vissman, NCHS

Barton McCann, M.D., HCFA

Meeting dates

Meetings held in Washington, D.C. .

March, 29-30, 1988

June 3, 1988, (working session)

November 4, 1988, (working session)

Meeting held in Easton, Maryland

October 12-14, 1988

\section{Functions and Process for the Executive Subcommittee, NCVHS}

\section{Background}

At the November 8, 1985, meeting of the NCVHS, based upon the recommendations of the Ad-hoc Subcommittee on Policy and Directions, there was established an Executive Subcommittee of the NCVHS. 
The Executive Subcommittee was established to assist the Chairman, NCVHS, in administering the activities of the NCVHS to facilitate and expedite accomplishment of policies determined by the full Committee and in providing liaison with governmental and non governmental organizations. The functions and procedures governing the Executive Subcommittee are subject to approval and modification by the full Committee.

\section{Composition}

The Chairman of the NCVHS is the Chairman of the Executive Subcommittee. Additionally, the Chairman, NCVHS, shall appoint, subject to ratification of the full Committee, three members to the Executive Subcommittee on an annual basis, with the option of reappointment, if appropriate. When appropriate, the three members will be selected one member each from those who have 1,2, or 3 years, respectively, remaining in their terms of appointment to the NCVHS. The NCVHS Executive Secretary, or designee, will be an ex officio member of the Executive Subcommittee.

\section{Functions}

Specific responsibilities of the Executive Subcommittee are to:

- Identify and recommend issues for full Committee and subcommittee attention.

- Develop Committee agendas, with a view towards planning several agendas in advance.

- Develop annual NCVHS Report.

- Coordinate and facilitate subcommittee activities.

- Advise National Center for Health Statistics or other appropriate agency on allocation of annual NCVHS budget and on resource needs for future years.

- Conduct other business delegated to it by the full Committee.

\section{Procedures and Process}

The Executive Subcommittee is empowered to act between full Committee meetings on those activities delegated to the Subcommittee, their actions subject to ratification by the full Committee.

Specific activities include:

1. In interim periods between the full Committee meetings of the NCVHS, the Executive Subcommittee will monitor, through telephone calls, mail, and/or meetings, the progress of work and other activities relevant to the current 
approved program of the full Committee. Working with staff and subcommittee Chairmen, activities will be facilitated, and problems and issues identified and resolved to accomplish the planned program.

2. The Executive Subcommittee will review work plans developed by the subcommittees and make recommendations to the full Committee.

3. The Subcommittee may confer with Chairmen of other subcommittees or with others to consider particular problems or issues impacting on the work of the full Committee. These may include senior personnel in the Department and other public and private agencies with interest in considerations appropriate to the responsibilities of the Committee.

4. Minutes of any meetings of the Subcommittee will be prepared and mailed to the full Committee membership and/or presented at the next full Committee meeting. If work progresses by mechanisms other than meetings, appropriate reports will be made to the full Committee membership.

5. The Chairman of the NCVHS or designee will report on the activities of the Subcommittee at each full meeting. This report will include an outline of the areas of concern of the Subcommittee and proposed plans for subsequent followup and activity.

6. In unusual events where some actions, previously not approved by the Committee, may be required by the NCVHS and a meeting has not been scheduled, the Subcommittee may consider alternatives and make recommendations to the full Committee by mail or telephone. With concurrence, approved actions may be taken by the Chairman or other formally appointed representatives of the Committee.

7. In the absence of the Chairman at an Executive Subcommittee or full Committee meeting, the Executive Subcommittee member with the most seniority on the NCVHS would act as Chairman. 


\section{Subcommittee on Medical Classification Systems}

\section{Current Roster}

Chairman

Karel M. Weigel, R.R.A.,

Division of Administrative Services

Mayo Clinic

200 S.W. First Street

Rochester, Minnesota 55905

William R. Felts, Jr., M.D.

Professor of Medicine

George Washington University Medical

Center

2150 Pennsylvania Avenue, NW,

Rm. 405C

Washington, D.C. 20037

William H. Kirby, Jr., M.D.

Principal

Health Management Services, Inc.

401 Walpole Court

Timonium, Maryland 21093

Joseph R. Martin

Director

Policy Evaluation, Economics, and

Health Data

American Hospital Association

840 North Lake Shore Drive

Chicago, Illinois 60611
Robert L. Mullin, M.D.

Director of Continuing Care

Hospital of Saint Raphael

1450 Chapel Street

New Haven, Connecticut 06511

Bruce Steinwald

Deputy Director

Prospective Payment Assessment

Commission

3007 th Street, SW, Suite 301-B

Washington, D.C. 20024

\section{Staff}

Richard Havlik, M.D., NCHS

Edward Bacon, Ph.D., NCHS

Eileen McCarthy, NCHS

Sue Meads, NCHS

Patricia Brooks, HCFA

Meeting dates

Meetings held in Washington, D.C.

March 21-22, 1988

July $25-26,1988$

\section{Charge to the Subcommittee on Medical Classification Systems}

It shall be the charge to this subcommittee to monitor, evaluate, and formulate recommendations, as appropriate, concerning progress in the following areas:

1. The progress toward the development of ICD-10; to review and evaluate areas where conflicting proposals emerge and to participate in the development of recommendations that are most compatible with priority concerns in the United States.

2. The progress of international decisions regarding ICD-10 as related to needs in the United States that would require the development of an ICD-10-CM. To consider alternative mechanisms and suggested time tables if an ICD-10-CM were perceived as necessary. 
3. The progress of activities moving toward the development of a single classification system for procedures in the U.S. to be used for physician fee-for-services, diagnostic reporting, and hospital inpatient care reimbursement that will respond to data user needs.

4. The ongoing refinement of diagnosis-related groups (DRG's), case mix indexes and severity indexes.

5. The progress in a number of related areas: systems for automated coding of medical diagnoses and improved medical terminology and nomenclature, quality of diagnostic data, and other related areas.

6. Continue to work with the existing ICD-9-CM Coordination and Maintenance Committee, chaired by the Health Care Financing Administration and the National Center for Health Statistics, to ensure the utility and integrity of ICD-9-CM in its broadly based multiuse applications throughout the United States. 


\section{Subcommittee on Long-Term Care Statistics}

\section{Current Roster}

\section{Chairman}

Laurence G. Branch, Ph.D.

Professor of Public Health

Boston University Gcrontology Center

67 Bay State Road

Boston, Massachusetts 02215

Stephen F. Gibbens

730 Arcady Road

Montecito, California 93108

Judith Miller Jones

Direclor

The National Health Policy Forum

2011 I Street, NW, Suite 200

Washington, D.C. 20006

Risa J. Lavizzo-Mourey, M.D.

Acting Director

Program in Geriatric Medicine

University of Pennsylvania

Ralston-Penn Center

3615 Chestnut Street

Philadelphia, Pennsylvania 19104-2683
David Mechanic, Ph.D.

Institute for Health, Health Care Policy, and Aging Research

Rutgers University

30 College Avenue

New Brunswick, New Jersey 08903

Staff

Richard Havlik, M.D., NCHS

Joan Van Nostrand, NCHS

Lynnette Araki, NCHS

Aurora Zappolo, OHPE, OASH

Frank Kirby, HCFA

Mary B. Cooper, HCFA

Meeting Dates

Meetings held in Washington, D.C.

January 19-20, 1988

July 19-20, 1988

October 19-20, 1988

\section{Charge to Subcommittee on Long-Term Care Statistics}

The care of the chronically ill and dependent is of increasing public policy importance. Demographic trends and reduced mortality are resulting in substantial increases in the number of older persons, especially the very old, and their share of the total population. The increasing prevalence of chronic conditions and dependency that accompanies aging implies substantial increases in the population needing long-term health care and personal services and raises serious concerns about the availability and affordability of such services. The absence of comprehensive financing concentrated in a single program has created difficulties in assembling information required for analysis of policy choices.

Similar concerns about information adequacy exist regarding care of the chronically mentally ill and the mentally retarded and developmentally disabled. Efforts to "deinstitutionalize" and "mainstream" have increased substantially the potential sources of care and, unfortunately, the potential for inadequate care. Increased fragmentation of the service system has also made collection of adequate data on these persons and their services more problematical. 
Therefore, the National Committee established a Subcommittee on Long-Term Care Statistics to describe and assess the adequacy of information available pertaining to long-term care policy issues and recommend steps to reduce any deficiencies. Specifically, the 1988-89 Charge for the Subcommittee on Long-Term Care Statistics is:

1. Review the Interagency Task Force report on the Long-Term Care Facility Minimum Data Set.

2. Review the Interagency Task Force report on the Long-Term Care Client Minimum Data Set.

3. Monitor the Forum on Aging's consideration of the National Research Council's recommendations in The Aging Population in the Twenty-First Century, especially the planning for a possible longitudinal health and retirement study and review of current functional classification techniques; consider those recommendations directed to the National Committee; and monitor general aging issues.

4. Monitor the development and review the Secretary's recommendation for a resident assessment instrument for nursing homes by Health Care Financing Administration as mandated by the Omnibus Budget Reconciliation Act of 1987.

5. Review recommendations for a proposed survey of board and care homes.

6. Initiate a review of quality of life assessment strategies in long-term care facilities.

7. Examine possible linkage of long-term care to mental health data bases.

8. Encourage better descriptions of bed supply rates for long-term care and their variation in the country. 


\section{Subcommittee on Ambulatory Care Statistics}

\section{Current Roster}

\section{Chairman}

William R. Felts, Jr., M.D.

Professor of Medicine

George Washington University

Medical Center

2150 Pennsylvania Avenue, NW

Washington, D.C. 20037

Judith Miller Jones

Director

The National Health Policy Forum

2011 I Street, NW, Suite 200

Washington, D.C. 20006

William H. Kirby, Jr., M.D.

Principal

Health Management Services, Inc.

401 Walpole Court

Timonium, Maryland 21093

Robert L. Mullin, M.D.

Director of Continuing Care

Hospital of Saint Raphael

1450 Chapel Street

New Haven, Connecticut 06511

\author{
Bruce Steinwald \\ Deputy Director \\ Prospective Payment Assessment \\ Commission \\ 300 7th Street, SW, Suite 301-B \\ Washington, D.C. 20024
}

Staff

Marjorie S. Greenberg, NCHS

Jim Delozier, NCHS

Stephen King, M.D., HCFA

Frank Kirby, HCFA

Janet Wise, HCFA

Mary B. Cooper, HCFA

Meeting dates

Meetings held in Washington, D.C.

January 11-12, 1988

April 26-27, 1988

August 15-16, 1988

October 3, 1988

Conference Call

November 30, 1988

\section{Charge to Subcommittee on Ambulatory Care Statistics}

1. Conduct a thorough and systematic review of the Uniform Ambulatory Medical Care Minimum Data Set (UAMCMDS) for the purpose ofdeveloping a revised version that meets current and anticipated needs. Carry out this review by receiving appropriate input from other governmental agencies, the research community, and the private sector.

2. Serve as liaison to the departmental interagency task force established to review the UAMCMDS from an internal perspective, comment on task force reports and deliberations, and react to task force recommendations.

3. Monitor and review the efforts of the Uniform Claim Form Task Force to investigate the definitions currently in use for place or site of ambulatory medical 
care service and to seek greater standardization in these definitions. Assure the timely input of other departmental agencies with related data activities into this process.

4. Provide continuing liaison with the Health Care Financing Administration, the National Center for Health Statistics, and other relevant agencies concerning the statistical aspects of physician payment systems and other data systems covering patient-provider encounters in ambulatory medical care settings.

5. Monitor these data systems and related activities by receiving periodic updates, having an opportunity to react to developments, and, where appropriate, framing recommendations concerning their future course.

6. Prepare an interim report to the NCVHS on the UAMCMDS by June 1988 and a final report by June 1989. 


\section{Subcommittee on Minority Health Statistics}

\section{Current Roster}

\section{Chaiman}

Mr. James K. Hutchison (1989)

Chief Actuary

The Blue Cross and Blue Shield

Association

676 North St. Clair Street

Chicago, Illinois 60611

Frederick A. Connell, M.D. (1992)

Acting Director

Maternal and Child Health Program

School of Public Health and

Community Medicine

University of Washington, SC-37

Seattle, Washington 98195

Jane L. Delgado, Ph.D. (1990)

President and Chief Executive Officer

National Coalition of Hispanic Health and Human Services Organizations

1030 15th Street, NW, Suite 1053

Washington, D.C. 20005

Joseph R. Martin (1990)

Director, Policy Evaluation, Economics, and Health Data

American Hospital Association

840 North Lake Shore Drive

Chicago, Illinois 60611
Risa J. Lavizzo-Mourey, M.D. (1989)

Acting Director

Program in Geriatric Medicine

University of Pennsylvania

Ralston-Penn Center

3615 Chestnut Street

Philadelphia, Pennsylvania 19104-2683

Staff

Jacqueline P. Davis, NCHS

Patricia Golden, NCHS

Diane Makuc, Ph.D., NCHS

Warren Hewitt, OMH, OASH

Olive Evans, HCFA

Meeting Dates

Meeting held in Washington, D.C.

May 10, 1988

Meeting held in Chicago, Illinois

October 17, 1988 (working session)

Conference Calls (working sessions)

February 19, 1988

February 29, 1988

March 14, 1988

April 26, 1988

May 2, 1988

August 29, 1988

\section{Charge to Subcommittee on Minority Health Statistics}

Recognizing the Committee's continuing interest in a valid and reliable national minority health data base, timely and relevant to key issues and accessible to both public and private sectors, and recognizing the Committee's perspective complementary to the Office of Minority Health, it shall be this subcommittee's charge to:

1. Work with and encourage the Office of Minority Health in the formulation of minority health data development and in the implementation of its work plan; report its progress to the Committee.

2. Review for adequacy the Department of Health and Human Services mechanisms for dissemination of minority health data. 
3. Identify and assess the Department of Health and Human Services data collection efforts in the planning stages toward determining ability to produce minority data.

4. Pursue with Health Care Financing Administration and the Social Security Administration the current and potential racial and ethnic identifiers in the Medicare and Medicaid data systems and bring this investigation to timely conclusion. 


\section{Subcommittee on Health Care Statistics}

\section{Current Roster}

\section{Chairman}

Mary Anne Freedman (1989), Director, Division of Public Health Statistics

Vermont Department of Health

P.O. Box 70

Burlington, Vermont 05402

Laurence G. Branch, Ph.D. (1992)

Professor of Public Health

Boston University Gcrontology Center

67 Bay State Road

Boston, Massachusetts 02215

David Mechanic, Ph.D. (1992)

Institute for Health, Health Care Policy, and Aging Research

Rutgers University

30 College Avenue

New Brunswick, New Jersey 08903

\section{Staff}

Edward L. Hunter, NCHS

Edward Bacon, Ph.D., NCHS

R. Clifton Bailey, Ph.D., HCFA

Meeting dates

Meeting held in Washington, D.C. September 15, 1988

Meeting held in Boston, Massachusetts

December 15, 1988 (working session)

\section{Charge to Subcommittee on Health Care Statistics}

The Subcommittee on Health Care Statistics is charged to:

1. Review the activities underway at the National Center for Health Statistics (NCHS) to develop the National Health Care Survey program. The Subcommittee should assist NCHS in obtaining sufficient internal and external input to the development and policy implication of the survey. As part of this process, the Subcommittee should assure that user needs are assessed and that appropriate priorities are set to respond to these needs.

2. The Subcommittee will coordinate its activities with other Subcommittees to assure that their concerns are considered in developing strategies and content for health care surveys.

3. Assume the Executive Subcommittee's current role of reviewing the status of uniform data sets not currently under study by a subcommittee. This review will focus on the adequacy of existing data sets to meet the proposed coverage by the National Health Care Survey. The Subcommittee will recommend to the Committee the need for review and/or revision of existing data sets or the development of new data sets. 


\section{Appendix V. Report of the Subcommittee on Long-Term Care Statistics: Activities from June 1987 to June 1988}

\section{Summary of Charge and Background}

The National Committee on Vital and Health Statistics (NCVHS) established the Subcommittee on Long-Term Care Statistics to describe and assess the adequacy of available information pertaining to long-term care policy issues and to recommend steps to reduce any deficiencies. During the period June 1987 to June 1988, there were five tasks in the Subcommittee's work plan:

1. Review of the reports of the Interagency Task Force on the Long-Term Care Facility Minimum Data Set and the Interagency Task Force on the Long-Term Care Client Minimum Data Set.

2. Review of nursing service classification systems and recommendations for possible inclusion in nursing home uniform data set.

3. Review of exemplary State data systems for nursing homes as models for implementation of a nursing home uniform data set.

4. Initiate review of health status classifications with the goal of assessing adequacy and recommending additional development and research as needed.

5. Review of a proposed survey of board and care homes to be conducted as followup to the 1990 Census.

The Subcommittee met September 28-29, 1987, and January 19-20, 1988, and heard testimony related to tasks 2 through 5 . The Subcommittee's conclusions and recommendations for each of these areas are summarized below. Task 1 , the review of the task forces' reports, was not undertaken as neither report was completed during this period.

\section{Nursing Service Classification}

During last year's review of the proposed Long-Term Care Minimum Data Set (LTCMDS), the Subcommittee recommended that additional review of the nursing service variable be undertaken before testing implementation of the LTCMDS within nursing homes. The current version of the LTCMDS provided only for a yes or no response to a general question concerning the use of nursing services during the past 
month. More detailed information could provide an indicator of patient health status, measure case-mix complexity and assist quality assurance oversight.

The Subcommittee found little consensus regarding a taxonomy for nursing services. The Subcommittee reviewed various lists of nursing services in use or being considered for implementation by the State Medicaid programs for reimbursement purposes. These included lists from Maryland, Minnesota, New York, Pennsylvania and Texas. The American Nurses Association provided an expanded list of services, and subsequently commented on and added to a staff prepared list (table 1). The list was also provided to other potentially concerned organizations for comment. No responses have been received from these organizations.

During this review, it became evident that a comprehensive taxonomy of nursing services did not exist. Further, the development of such a taxonomy was neither an appropriate nor feasible task for the Subcommittee and the Committee. The Subcommittee's objective was to identify the subset of nursing services that distinguish some nursing home patients as being extraordinary in terms of health status and/or resource needs. However, the Subcommittee feels development of a comprehensive taxonomy should be encouraged. Its availability would have been very useful to the Subcommittee in developing the service list for the LTCMDS. Such a taxonomy would have many other applications as well.

For purposes of the LTCMDS, the Subcommittee concluded that a list of services comparable to those used by Medicaid case-mix reimbursement systems would be appropriate for the testing period. The list that will be used by the Health Care Financing Administration in an eight-State demonstration of such systems was selected (table 2). The list is a derivative of those developed in New York and Texas and will have the broadest implementation of any of the lists examined. It is important to recognize that this list was developed for the purposes of Medicaid reimbursement and reflects the mix of patients supported by that program. These patients tend to be long stayers with primarily custodial care needs. Medicare and private patients may use specialized nursing services not included on this list. Consideration should be given during the test period to the addition of some of these services. Furthermore, continued monitoring of services provided by nursing homes should be undertaken to modify the list to reflect shifts in patterns of care.

\section{Recommendations}

1. The NCVHS should recommend to the Assistant Secretary for Health (ASH) that the attached list of services be incorporated into the LTCMDS in place of the nursing service item. Review of the nursing service list should be undertaken to assure that it includes the principal skilled services used by non-Medicaid patients. Periodic reviews should be undertaken to assure it reflects changes in patterns of care. 
2. The NCVHS should recommend to the ASH that a process be established with joint public and private sector cooperation to develop a multipurpose nursing service taxonomy.

\section{State Nursing Home Data Systems}

The Subcommittee attempted to identify and review patient-level nursing home data systems maintained by different States. The scope of the review included the system's content, collection, storage and retrieval procedures, and examples of utilization for different purposes. The objective of this review was to determine what lessons there may be in State experiences that would affect the design or implementation of a LTCMDS.

The Subcommittee's review was conducted primarily through national associations of State Medicaid agencies and State data organizations. A more intensive review involving a survey of different agencies within all 50 States was not conducted at this time.

Patient-level data systems, especially computerized data systems, appear to be quite limited. State Medicaid programs do collect patient-level data as a component of their responsibility of certifying providers and monitoring quality and appropriateness of care. These data represent an important source of information on nursing homes because Medicaid programs finance care for approximately 60 percent of patients. However, very little of these data are computerized; and even when computerized, the data are not used extensively for policy analysis.

The Subcommittee also attempted to identify data systems that extended beyond the Medicaid program to include Medicare and other pay categories, especially private pay. A system in Connecticut was noteworthy in that it has been in operation since 1977 and has collected repeated patient-based information on all patients in Connecticut nursing homes. Modifications and additions have been made with, for example, questions on activities of daily living being added more recently. Tracking of patients within the system is possible so that accurate length-of-stay data are available. Information that Florida was developing a general computerized system for nursing home patients could not be confirmed.

Identification of additional information on State data systems will likely require a survey of State agencies. The Subcommittee believes identification of exemplary systems is a worthwhile activity. Such systems would serve as models for the collection, storage, and retrieval of vast amounts of administrative data on nursing homes. At present, these data remain a virtually untapped resource. The Subcommittee's identification of such systems would serve a very useful purpose. As our attempts at identifying such systems indicate, their existence is not widely known. 
The NCVHS should recommend that the Subcommittee continue its review of State data systems for nursing homes. The priority given this review should be conditional on the other tasks assigned the Subcommittee.

\section{Measurement of Health Status}

Unlike acute care-where diagnostic information is highly predictive of service needs, health status, and outcomes - individuals' long-term care needs and status are better measured by the degree of functional impairment. Impaired functioning is the final common pathway of many physical and mental conditions. Measures of functional status are widely used in long-term care policy development and planning, epidemiological research, and clinical applications.

During its review of the Long-Term Health Care Minimum Data Set, the Subcommittee noted many concerns about the use of functional status measures, in particular activities of daily living and instrumental activities of daily living variables. There appeared to be great variation in the application of these measures and no clear understanding of how this variation affected the statistics collected.

The Subcommittee held a meeting with four researchers expert in the measurement of functional status. The purpose of the meeting.was to assess what methodological research had been undertaken and what consensus might exist regarding preferred methods of measurement. No significant areas of consensus were identified because of the very limited volume of prior methodological research. However, the meeting was very useful in identifying areas that should be investigated. These are summarized in table 3.

The Subcommittee believes that methodological research on functional status measures should be encouraged and funded. In addition, much greater effort should be made at disseminating the results of such research to those involved in data collection activities.

Identification of superior methods for measuring functional status should be a long range goal. Superior methods would be those demonstrated to produce more valid, reliable, consistent, and useful statistics in a variety of applications. Adoption of these superior methods would improve comparability of statistics across data sources. Mandating their adoption in some contexts, such as in federally sponsored surveys, is not appropriate. Individual applications may require special considerations and continued experimentation is essential to further development and refinement of functional measurement. 
A National Institutes of Health Consensus Development Conference on Geriatric Assessment Methods for Clinical Decisionmaking was held in October 1987. Their objective, use of assessment for treatment and care of individual patients, differed from the Committee's interest in the collection of population statistics. However, they reached a similar conclusion. "In domains in which there are multiple validated instruments to measure the same function, there have not yet been studies that directly compare one method to another." "Further their recommendations included:

- Use controlled trials of comprehensive geriatric assessment to evaluate the effect of different combinations of personnel, instruments and interventions.

- Directly compare instruments that assess information within the same domain.

\section{Recommendations}

1. The NCVHS should indicate to the ASH the need for research on functional status measurement. It should request that ASH encourage key agencies, such as the National Center for Health Statistics, the National Center for Health Services Research and Technology Assessment, the Health Care Financing Administration, the National Institute on Aging, and the National Institute of Mental Health to fund methodological studies either independently or as a component of other research activities. Finally, the NCVHS should request that the ASH encourage the Health Information Policy Council or Interagency Forum on Aging to consider establishment of an ongoing process to identify and disseminate superior methods of measuring functional status.

2. The NCVHS should, on a biennial basis, review ongoing activities in this area and make additional recommendations if appropriate.

\section{Board and Care Homes}

Board and care homes represent an important source of long-term care for the elderly, the chronically mentally ill, and the mentally retarded and developmentally disabled. More than 500,000 persons reside in these facilities. Board and care residents have a wide range of conditions and associated medical, nursing, and custodial needs. Patterns of care provision also vary widely as some facilities employ inhome nursing staff, others maintain ongoing relationships with community care sources, such as home health agencies, and others have no ongoing medical or nursing care. Public monies provide considerable support for these facilities through the Supplemental Security Income Program, Medicaid, and other Federal and State programs. 
Despite their significant role in the provision of long-term care and the sizable public investment in them, information on these facilities and their residents is extremely limited and fragmentary. Surveys that have been undertaken have generally confined their scope to licensed or certified facilities. Licensing and regulation is a State and local government responsibility, and there is considerable variation in these requirements. In some areas, virtually all facilities must be licensed; and in others, almost none are.

The problem of collccting data on unlicensed facilities was illustrated by a survey in Ohio. Using knowledgeable sources, a potential universe of about 1,000 board and care homes was identified. When contacted, only one-quarter were determined to be opcrating as board and care homes.

The Subcommittee heard testimony regarding a possible followup survey to the 1990 census to identify board and care homes and collect data on their operations and residents. The survey would be a joint undertaking by the Department of Health and Human Services and the U.S. Census Bureau. Households with three or more unrelated individuals would be contacted and surveyed to determine if they were board and care facilities. Detailed plans for the survey have not been made, nor has a decision about whether it will be undertaken.

The followup survey could provide significant information on small unlicensed board and care homes. Identifying these homes through the decennial census is probably the most efficient means of doing so. Many board and care homes will not be included within the scope because they are classified by the Census Bureau as group quarters or institutions, not households. The Subcommittee feels that it is important to take advantage of this followup survey to obtain a comprehensive picture of the board and care industry. Comparable data should be collected from all types of board and care homes, regardless of how they are classified for census purposes.

\section{Recommendation}

The NCVHS should indicate to the ASH its support for efforts to improve information on the board and care industry. Further, it should request that it be informed of developments regarding the potential followup survey to the 1990 census and encourage the expansion of the survey's scope to cover the entire board and care industry. 


\section{Table 1}

\section{Nursing Services for Taxonomy}

Prepared by: Subcommittee on Long-Term Care Statistics with Assistance from American Nurses Association

$$
\text { Nursing Services }
$$

Indicate general types provided to patient during the past month.

A. Treatments and Procedures (Skilled, Special, Preventing Complications)

1. General Medical

a. Monitor/Detect Fluctuating Medical Conditions

\section{Excretory}
a. Catheter Management
b. Manage Impaction
c. Ostomy Care
d. Behavioral Management to Maintain Continence.

(Maintaining continence can prevent complications of pressure sore and urinary tract infection among nursing home patients.)

3. Medications
a. Pain Control
b. Administer/Monitor Medications
c. IV Medication and Therapy

4. Complex Therapies
a. Chemotherapy
b. Radiation Care
c. Dialysis
d. Blood Transfusion

5. Skin Lesions
a. Dressing 

b. Wound Care
c. Pressure Sore Management and Treatment (Decubitus old term)
d. Heat Treatment

6. Respiratory
a. Suctioning
b. Respiratory Therapy
c. Oxygen Administration
d. Ventilator Assistance
e. Tracheostomy Care

7. Special Nutrition
a. Enteral Nutrition

8. Application and Management of Restraints

9. Other

a. Specify

B. General Care (Maintenance and Rehabilitation, Quality of Life)

1. General Skin and Musculoskeletal
a. Prevention and Treatment of Pressure Sores
b. Turn and Position
c. Range of Motion
d. Application Treatments and Therapies
e. Application of Adaptive Devices - Splints, Etc.

2. General Nutrition
a. Diet Management
b. Intake and Output/Fluids

3. ADL Management
a. Ambulation Management
b. Dressing Management
c. Transfer Management 
d. Safety Management

e. Incontinence Management

f. Eating

g. Hygiene/Grooming

4. Establish Communication

5. Assessment

a. Quality of Life/Quality of Care

b. Patient Advocacy

c. Discharge Planning

d. Care Management

e. Coordinate Hcalth Care Team

f. Availability, Willingness, and Ability of Informal Caregivers

6. Daily Assessment

a. Mental Status/Behavior

b. Skin Integrity

c. Respiratory Function

d. Cardiovascular Stability

e. Functional Status Regarding ADL's and IADL's

f. Response to Medications and Therapies

g. Eating/Nutrition/Hydration

h. Laboratory Data/Diagnostic Studies (when ordered)

7. Oral Hygiene

8. To be Determined

9. Other

a. Specify

\section{Psychosocial Activities}

1. Mental Status Assessment

2. Interventions 

a. Reality Orientation
b. Sensory Stimulation

3. Sleep Disturbance Management

4. Support Death and Dying

5. Family Support

6. Patient Support
a. Illness Adjustment Promotion
b. Build Self-Esteem

7. Spiritual Support

8. Management of Cultural Variations

9. Management of Behavioral Disturbances
a. Memory Deficits
b. Wandering
c. Violent Behavior/Physical Aggression
d. Suicidal Behavior
e. Depression
f. Withdrawn Behavior/Regressive Behavior

(This area has been documented as the single most difficult problem for nursing staff to manage. Skilled nursing is needed to determine humane and therapeutic technique to manage the difficult patients without the undo use of chemical and physical restraints.)

10. Evaluation of Participation in Recreational Activities (with Recreational Therapist)

11. Other
a. Specify

D. Education/Training

1. Bowel and Bladder Training

2. Medication Training and Education 
3. Caregiver Training and Education

4. Discharge Planning and Coordination of Home Care Services with Social Services

5. Instruction in Performance of ADL's

6. Instruction and Observation of Treatments and Therapies to be Performed at Home (e.g., Intravenous therapy, dressings)

7. Instruction in Use of Adaptive Aides (e.g., Walker)

.8. General Health Promotion Activities (e.g., Smoking Cessation, Diet, etc.)

9. Control of Institutional Environment
a. Environmental Safety
b. Infection Control
c. Coordination of Resident Evacuation
d. Liaison and Contact Person/Staff for Outside Medical Care

1) Physician

2) Laboratory Services

3) Radiology, Etc.

e. Nursing Documentation of Care and Maintenance of Medical Record

f. Family Contact/Liaison to Institution for Care Delivered and Resident's Response to Care 
Table 2

\section{Services and Treatments Section \\ Multistate Case Mix Demonstration (HCFA) \\ Data Elements List \\ Draft March 1988}

Services and Treatments

Measure what the resident actually has been receiving during the past 4 weeks. This is not what the resident should be receiving but the services and treatments the resident has been receiving. These services must be documented in the patient record and, where appropriate, provided on a one-to-one basis or in small groups [five (5) or less people]. For each treatment or service, several different items of information are recorded. If the patient is receiving a service, record all pieces of information requested. If the patient is not receiving a service, leave all data requested blank.

Specialized Medical Treatments.-For the medical treatments listed below, record the frequency that the patient receives the service and the location codes presented below to record your response.

Frequency Codes

$$
\begin{aligned}
& 1=\text { Less than once per week } \\
& 2=1-6 \text { times per week } \\
& 3=\text { Once per day provider } \\
& 4=2 \text { times per day } \\
& 5=3 \text { or more times per day }
\end{aligned}
$$

\section{Treatment}

Frequency

$1=$ In nursing facility by staff

2 = In nursing facility by other

3 = Out of nursing facility

Cancer chemotherapy

Blood transfusions

Dialysis

IV Therapy

Physician's visits

\section{Nursing Services}

For each nursing intervention or treatment residents receive or complete themselves, enter the frequency code from the codes listed below and the intervention code that identifies whether patients complete the service themselves or receive training in self-care for the procedure. 
$1=$ Less than once per week

$2=1-6$ times per week

$3=$ Once per day

$4=2$ times per day

$5=3$ or more times per day

\section{Treatment}

Injections

Collection of specimens for Lab Test

Pain management program

Oxygen administration

Respiratory care (daily respirator maintenance, hand held nebulizer treatment, IPPB)

Oral/nasal suctioning

Tracheostomy care/suctioning

Thoracic drainage

Gastrostomy/Nasal Gastric Tube Care

Parenteral Hyperalimentation

Gastric Suctioning

Intake/Output Measurement

Training in Eating

Sterile Dressing(s)

Unsterile Dressing(s)

Skin care for stasis ulcer

Skin care for decubitus ulcer

Preventive skin care

Urinary catheter care

Ostomy care (colostomy, ileostomy)

Bowel and bladder training

Ambulation/transfer practice

Brace/splint/prothesis assistance \& care

Contracture Prevention Care

Dressing and Grooming training

Other rehabilitation nursing (ROM, heat, exercise)

Reality orientation

Sensory stimulation

Isolation precautions

Family counseling

Discharge preparation
Frequency Intervention

$1=$ Self care

$2=$ Staff completes

$3=$ Staff completes, training patient 
Issues in functional status measurement

- Which domains of mental and physical functioning are essential to characterizing an individual's status?

- How should differences in capacity versus difference in performance be ascertained? Which causes of nonperformance need to be distinguished-health, culture, tradition, education, preference?

- How are prevalence rates affected by the use of broad activities descriptions, e.g., eating, dressing, going outside, or shopping? (Each activity involves multiple components and persons may have difficulty with some aspects, but remain able to accomplish the overall task.)

- Does partial impairment, "has difficulty," need to be distinguished from total impairment "can not do?"

- What aspects of timing need to be identified-time since onset, frequency, and time of day (day versus night)?

- How does a respondent's current residence (institution versus community) affect responses?

- How do data collection methods affect responses? Data are collected from patient records, knowledgeable sources (e.g., nurses or aides), individuals themselves, and other proxies?

- In surveys, how does mode of administration, telephone versus in person, affect responses?

- How does instrument design-question structure and order, use and content of explanatory prefaces, overall context-affect responses?

- In measuring assistance, how should adequacy relative to need (excessive or inadequate) be assessed?

- What methods of summarizing impairment data, e.g., use of scales, profiles, etc. are valid? In which contexts are different summary methods useful?

\section{Reference}

${ }^{1}$ Office of Medical Applications of Research, Geriatric Assessment Methods for Clinical Decisionmaking, National Institutes of Health Consensus Development Conference Statement, Vol. 6, No. 13, October 19-21, 1987. 


\section{Appendix VI. Report on Minority \\ Health Statistics}

\section{Introduction}

The 1985 Secretary's Task Force Report on Black and Minority Health provided the best contemporary analysis of data on the health status of minority populations. In reporting the phenomena of excess deaths, it not only provided a framework to relate minority health status to that of white persons, but offered a means to define more satisfactorily the quantitative nature of this health disparity. However, in reporting these findings of racial and ethnic disparities, the Task Force further noted that, although there is strong empirical evidence to sustain the existence of the health status disparity between ethnic and racial minority populations and nonminorities with respect to mortality, morbidity, health status, and health utilization, more detailed data are needed to "... enhance our understanding of the processes underlying the disparity and to provide a better basis for rational program planning, implementing and monitoring." Consequently, one of the major Task Force recommendations centered around the need to improve and more fully utilize available sources of data. Specifically, this recommendation urged:

- DHHS should undertake activities that would improve existing sources of health data such as enhancing cooperative efforts with the States in recording vital statistics, incorporating specific racial and ethnic identifiers in data bases, and oversampling selected minorities in national surveys.

- Furthermore, the Department of Health and Human Servvices should support innovative uses of currently available data consistent with the Privacy Act and confidentiality constraints. Analyses such as cross-comparisons from different data sets and specialized studies should be encouraged because they can contribute to understanding the health status and needs of minority populations.

With the processes well underway to develop goals and objectives centered specifically on minority populations as well as the broader effort to define new health goals and directions for the Nation for the year 2000, it is important that, in structuring these goals and monitoring performance, the data be as complete as possible about all segments of U.S. population, in particular racial and ethnic minorities. It is important that there be a data collection policy which implicitly acknowledges the importance that ethnic and racial data has in the public health planning process. 
The capacity to formulate effective policies directed at prevention, education and treatment for ethnic and racial minority populations is driven to no less extent than is true for the general population by the quality of the data analyzed. In order to achieve the optimal depth of consideration, to explore the widest possible range of public policy alternatives with respect to cost, efficacy, efficiency and expected outcome, it is imperative that the public policy decisionmaking process be based on the most thorough and current data that are possible to obtain. For those racial and ethnic minority populations, the continued paucity of data and analysis of key health indexes seriously compromise and impair the quality of decisions designed to ameliorate the longstanding disparity in their health status.

Since the publication of the Task Force report, some efforts have been made to expand the data available on racial and ethnic minority populations; most notable is the oversampling of Hispanic Americans during the National Health and Nutrition . Examination Survey. However, although these and other efforts do expand our collective knowledge of the nature of these health status disparities, there continue to be a number of areas and possible opportunities where further improvement can be achieved in collecting and analyzing racial and ethnic data. These opportunities provide the greatest single opportunity to illuminate better and more effective measures both to understand and devise strategies to reduce excess morbidity and mortality in these populations.

\section{Hearing}

The Subcommittee on Minority Health Statistics of the National Committee on Vital and Health Statistics conducted a hearing on May 10, 1988, in the Hubert H. Humphrey Building to receive testimonies on the unmet statistical data needs for research and policy formation on minority populations and the medically indigent. Presentations were made by members of both the public and private sectors.

\section{Summary of Findings}

The testimonies presented at the Subcommittee's hearings reemphasized that the data issues raised by the 1985 Secretary's Task Force on Black and Minority Health continue to require attention by the Department. All presenters recognized the need for racial and ethnic identifiers in the health data collected by the Federal Government and the private sector citing the following reasons:

- To provide a more accurate assessment of the health status of various subgroups of the population.

- To evaluate health services access and utilization of various system components. 
- To measure the impact of targeted policy initiatives.

- To record the interaction of poverty, race, and ethnicity on health status and identify possible inequities in health care across groups.

- To track the racial and ethnic features of the aging population to record the utilization requirements, cultural influences, and behavior of different population groups.

- To determine whether patterns of care, numbers of visits, per capita costs, and health outcomes differ by race and ethnicity.

Presenters made several points regarding racial and ethnic identifiers in the Medicare and Medicaid files:

- There is a need to analyze Medicare and Medicaid data by race and ethnicity to:

1. Determine whether patterns of care, numbers of visits, per capita costs, and health outcomes differ by race and ethnicity.

2. Enable those who set health care reimbursement policy to measure the impact of their decisions upon different minority populations.

3. Determine why expenditures on minority recipients are less than those for nonminority recipients.

- Racial and ethnic data should be collected as a part of the eligibility determination and enrollment process rather than by the providers on claims forms.

Many presenters identified issues that need to be addressed in the use of racial and ethnic identifiers:

- There are inaccurate uses of race as a variable when all minorities are lumped into one category (e.g., including Hispanics or other minorities in the white category).

- There is a need to standardize racial and ethnic reporting categories.

- There is a need for oversampling and special studies and surveys to insure adequacy of survey sampling of minority populations.

Most presenters felt that such data would have the following impact on the formulation of new or expanded research and demonstration efforts:

- Gathering data on racial and ethnic identity may trigger more detailed or local studies of reasons for differences across groups that are not evident from national survey analyses. 
- Including race and ethnic information in person-level data will allow the use of race and ethnic adjustors to be tested.

- Racial and ethnic information will help to prioritize, target, and evaluate the efficacy of the research funds being spent.

- Racial and ethnic information can contribute to studies on the financing and management of AIDS and to evaluating alternative delivery system methods such as health maintenance organizations.

\section{Recommendation 1:}

To provide the capability for policy analysis and research on health issues related to minority populations, all person-based health data systems supported or maintained by the Department of Health and Human Services (DHHS) should make possible racial and ethnic identification in a uniform fashion.

\section{Rationale}

Recommendation applies to all current and future health data collection efforts supported or maintained by the Department. Racial and ethnic disparities in health status remain a cause for serious concern. To support a wide attack on the problem, all DHHS agencies with control over data need to examine how their data resources can reinforce the effort. Although many data systems of the Department currently include racial and ethnic identifiers, certain major systems do not. For example, the Medicaid program, which operates under Federal guidelines to provide medical assistance for certain needy and low income persons, does not currently utilize uniform guidelines for the collection or reporting of data on race or ethnicity.

A directive (\#15) from the Office of Management and Budget (OMB) provides for standard classification for recordkeeping, collection, and presentation of data on race and ethnicity in Federal program administrative reporting and statistical activities. These standardizations were developed to provide for the collection and use of nonduplicated, compatible, and exchangeable racial and ethnic data by Federal agencies. Health data are frequently linked to other sources, such as census data to produce population based rates. Unless racial and ethnic coding is comparable, stratification by race is impossible. Although the race and ethnic categories mandated by OMB are broad, many federal data bases fall short of meeting them.

The testimonies presented to the Subcommittee, Public Law 94-311, and the findings from the 1985 Report of the Secretary's Task Force on Black and Minority Health reinforce the value of uniform or standard coding of racial and ethnic data in health records. It is recognized that this recommendation will require enhanced dissemination of these guidelines and educational efforts to ensure compliance with proper coding practices. 
To promote adequate precision of health statistics on minority populations, the Secretary should:

- Continue to support the practice of oversampling minorities in national surveys when appropriate.

- Periodically review the status of newly planned national surveys of health data to ensure that all considerations are being made to provide adequate sample sizes for minority populations.

\section{Rationale}

Testimonies presented at the Subcommittee's hearings reemphasized that the limitations of sample size of many national surveys are such that analyses of certain racial and ethnic groups cannot be performed. This seriously limits the ability to pinpoint need, design effective programs, and form sound health policy and programs at the Federal, State and local levels.

\section{Conclusion}

The Subcommittee makes these recommendations based largely on the testimonies heard and on its collective judgment. These recommendations are similar to those previously made in the 1985 Report of the Secretary's Task Force on Black and Minority Health, reinforcing the fact that there are major issues concerning minority health data that remain unresolved.

The Subcommittee has devoted considerable attention to the adequacy of racial and ethnic identifiers in the Medicare data systems. Before 1980, only distinctions between white and all other races were recorded. Since 1980, the Social Security Administration has collected racial and ethnic identifiers on new applicants, and these data can satisfactorily be linked to Medicare data for these persons. Nevertheless, data on persons enrolled in Social Security prior to 1980-that is, the majority of current Medicare beneficiaries-do not include adequate racial and ethnic identifiers. Therefore, currently and for many years into the future, analysis of the utilization, expenditures, and outcomes by race and ethnicity will not be possible for a substantial segment of Medicare beneficiaries. Although this problem will diminish progressively over the next three to four decades, the Subcommittee is concerned that this is too long to wait.

The Subcommittee made a recommendation to the Health Care Financing Administration (HCFA) earlier this year to consider obtaining racial and ethnic information in the Medicare claims forms. Dr. Roper, Administrator of HCFA, responded to the 
recommendation by stating that the HCFA billing forms are not the appropriate instruments to use to collect these data. He stated that the volume of input, the reconciliation of conflicting data, the expense of initial data development, and the data maintenance and retention argue against collection of these data on a billing form as costly and unreliable.

Although the Subcommittee now agrees the Medicare claims forms may not be the most appropriate place for the collection of race and ethnicity, the Subcommittee believes that other alternatives must be considered by HCFA. The need for the racial and ethnic data warrants every avenue being explored by HCFA. The Subcommittee will continue to pursue this issue with HCFA. 


\section{Appendix VII. Report of the Work Group on Data Dissemination Issues}

The Work Group on Data Dissemination Issues was created in June 1987 and charged with preparing a white paper on issues associated with the quality of data released by agencies within the Department of Health and Human Services (DHHS), either purposefully or under the Freedom of Information Act (FOIA); with making recommendations for addressing these issues; and with making suggestions on how the Committee might move more broadly into the data dissemination area.

The Work Group requested and received extensive information from all Public Health Service agencies within DHHS and from the Health Care Financing Administration (HCFA). Agencies provided their written policies on responding to FOLA requests, conducting data analyses; and releasing statistical information, including published reports, studies, and public use data tapes. The Work Group noted that, although agencies have written policies regarding FOIA requests, they do not necessarily have written guidelines for the voluntary release of data. Some general guidelines on data collection and analysis have been prepared by the National Center for Health Statistics (NCHS) and the Office of Federal Statistical Policy and Standards; no other agencies contacted appear to have similar written guidelines. In phone conversations with NCHS staff, agencies described a variety of informal approaches for reviewing the quality of study designs and data releases. Many agencies do have written guidelines related to confidentiality of data and the Privacy Act.

The Work Group held a working session on October 7-8, 1987, and decided to separate the issues into two parts: voluntary disclosures and responses to FOIA requests. Because the preliminary review indicated that agencies have adequate guidelines in place to respond to FOIA requests, the Work Group concentrated its efforts in the areas of voluntary disclosures. The Work Group also decided, with the approval of the full Committee, to gather more information on public use data tape policies and practices.

On March 28, 1988, the Work Group on Data Dissemination Issues held a public meeting to address the issue of variation among agencies in the timing and availability of information disseminated through mechanisms of public use data tapes. The following DHHS agencies made presentations: National Center for Health Statistics; National Center for Health Services Research; Health Resources and Services Administration; Food and Drug Administration; National Institute of Child Health 
and Human Development; Health Care Financing Administration; Alcohol, Drug Abuse, and Mental Health Administration; Centers for Disease Control.

Prior to the meeting, the Work Group identified several issues that the agencies were asked to address. The issues focused on the following

- How agencies determined priorities of format for data dissemination and timing of data release.

- Whether impediments were encountered in producing and releasing public use data tapes.

- General availability of data and the extensiveness of data tapes when released.

- Whether prerequisites were made of requestors or whether conditions and/or limitations were made in the utilization of the data.

- Types of procedures and statistical measures employed to ensure confidentiality of information identifying individuals or establishments.

- Extent to which users of the agencies' data bases utilize public use data tapes versus hard copy reports.

- Whether the availability of public use data tapes would decrease the number of data requests to the agencies.

- Availability of data collected or compiled under the grant mechanism.

Responses to the issues posed at the public meeting indicated that, in general, agencies felt that public use data tapes served as effective means to disseminate information to the public because they provided users with considerable information and the ability to do their own analyses. However, with the exception of HCFA, the tapes did not reduce the number of data requests that agencies received. A major impediment cited by these agencies is the significant amount of resources that are required to produce public use data tapes, particularly with respect to the documentation requirements established by agencies. Criteria for documentation also reflect a fair amount of variation among agencies. A detailed discussion of the participating agencies' public use data tape programs can be found in the minutes of the public meeting.

While the Work Group was in the process of carrying out its review, the Office of Management and Budget (OMB) issued draft guidelines on Federal statistical activities that the Work Group examined in some detail.

Based on the materials reviewed, the OMB draft guidelines, and the information collected at the public meeting, the Work Group made several recommendations: 
1. If a user is to be able to utilize Government information intelligently and contribute to scientific inquiry, the user must have sufficient information about the data being accessed. In addition, some Government studies make statements about the status of private persons or institutions. In these cases, the potential "injured party" has need of all information about the study in order to provide for due process. For these reasons, the Work Group recommends that, when a DHHS agency voluntarily releases tabulations, analyses, or studies, the agency should provide full documentation of study methodologies to the user at the time of data release. If a study is prereleased to affected parties for review and comment, methodology should be made available during the prerelease period.

Information regarding data imputation and the use of proxy responses should be part of the project documentation. On public use data tapes, records with imputed values or proxy interviewees should be flagged.

Although its charge was to make recommendations pertaining to data releases by DHHS agencies, the Work Group considers these to be reasonable expectations for data releases by the private sector as well.

Information released under FOIA presents a special problem. Although it would be desirable for agencies to release full documentation at the time a study is released in response to a FOIA request, the agency may be unable to provide this documentation. Therefore, the Work Group recommends that, when data, analyses, or studies are released under FOIA, the agency should, as a minimum, incorporate all pertinent caveats and disclaimers into the data release. In addition, whenever possible, affected parties should have an opportunity to review and comment on the accuracy of the data released, even if this requires seeking an extension of the 10-day release deadline.

2. The Work Group did not address the adequacy of guidelines developed by the specific agencies because it felt that the $\mathrm{OMB}$ guidelines were very inclusive and would be the model for any specific agency guidelines. The Work Group supports the concept of the proposed guidelines but recommends that the focus of implementation of these guidelines be conducted through policies and procedures developed by the Department rather than by OMB.

3. Public use data tapes are an important resource for many users of Federal data. The availability of data through this mechanism is especially important in light of the fact that many DHHS agencies do not have adequate resources to analyze fully the data they collect. Data tapes also permit replications of scientific findings. Preliminary staff efforts to determine what agencies have public use tapes and how these agencies made them available indicated that policies regarding the dissemination of data through public use tapes are agency-specific. Whereas some agencies produce a large number of data tapes, others produce few or none.

The Work Group supports the dissemination of data through public use tapes and urges agencies to develop positive policies towards dissemination of data in this form. To this end, the Work Group encourages all DHHS agencies that 
collect data to establish criteria for determining whether to produce public use data tapes as wcll as a process for producing and disseminating the tapes. This recommendation specifically is addressed to data collections sponsored by the agencies that can be used in statistical research. Although the Work Group discussed policics and practices for data collections carried out under the grant mechanism, it did not feel that it was in a position to make recommendations in the grant area.

The Work Group supports the 90-day language in the OMB guidelines for release of public use data tapes after release of the first published report and encourages agencies to develop procedures to implement this guideline.

In the interest of enhancing the dissemination of data, the Work Group recommends that agencies consider the utilization of resources available to them to publicize the marketing of these data tapes. Some of these mechanisms also include the devclopment of hard copy documents and online data systems.

4. Diagnostic information is an important component of several major Federal data systems. Accurate diagnostic data are essential for analyzing morbidity and mortality patterns. They are needed for assessing the quality of care delivered and the appropriateness of the setting used, for developing case mix and severity indexes, and for a variety of other classification purposes. Currently, known inaccuracies in diagnostic data result from inappropriate coding conventions, lack of coder training, and lack of coordination in disseminating information about code changes. Of equal concern is the quality of the input document from which the diagnoses are coded. For these reasons, during the coming year, the Work Group recommended and the full Committee concurred that the NCVHS Subcommittee on Medical Classification Systems should address issues related to the accuracy of the diagnostic information obtained and coded according to ICD-9-CM.

5. The National Academy of Sciences Committee on National Statistics (CNS) has developed a proposal to study the issues of confidentiality and data access through an expert panel. Because the concerns of CNS are similar to those of the NCVHS, the Work Group recommends establishing an ongoing liaison with CNS to specifically monitor the panel study.

With the submission of this report, the Work Group has completed its charge as assigned by the Committee and recommends the dissolution of its appointment. However, the Work Group recognizes that data dissemination is an important area for the Committee to monitor; thus, it recommends that the Executive Subcommittee continue to monitor the responses to these recommendations from the Department. 


\section{Work Group on Data Dissemination Issues}

Roster

\section{Chairman}

Mary Anne Freedman (1989)

Director

Division of Public Health Statistics

Vermont Department of Health

P.O. Box 70

Burlington, Vermont 05402

Joseph R. Martin

Director

Economic and Policy Studies

American Hospital Association

840 North Lake Shore Drive

Chicago, Illinois 60611

Robert L. Mullin, M.D.

Director of Continuing Care

Hospital of Saint Raphael

1450 Chapel Street

New Haven, Connecticut 06511
George C. Myers, Ph.D. (1988)

Director

Center for Demographic Studies

Duke University

2117 Campus Drive

Durham, North Carolina 27706

\section{Staff}

Lynnette Araki, NCHS

Marjorie S. Greenberg, NCHS

Wayne Kazmarkiewicz, HCPA

Frank Kirby, HCFA 


\section{Background Materials for NCVHS Workgroup On Data Dissemination issues}

\section{National Center for Health Statistics (NCHS)}

"NCHS Staff Manual on Confidentiality." DHHS publication No. (PHS) 84-1244, September 1984.

This manual presents a set of laws and regulations that exist to require and/or permit the National Center for Health Statistics to maintain the confidentiality of records.

Sirken, Monroe G. et al. "Manual on Standards and Procedures for Reviewing Statistical Reports." Washington, D.C., National Center for Health Statistics, 1983.

This manual presents the technical standards for preparing statistical reports and the protocols for applying these standards in the technical review process.

"Legislative Authorities for the National Center for Health Statistics." Hyattsville, MD, National Center for Health Statistics, July 1985.

Included are Sections 304, 306, 307, and 308 of the Public Health Service Act.

"NCHS Systems of Records Notices." Federal Register Vol. 51, No. 226, November 1986, \& Vol. 49, No. 187, September, 1984.

Includes Federal Register notices that describe routine uses of records maintained in NCHS' system and states the policies and practices for storing, retrieving, accessing, retaining, and disposing of records in the system.

"Guidelines for the Presentation of Errors in Data of the National Center for Health Statistics." NCHS Staff Manual Guide Publications and Printing No. 2, March 13, 1978.

This guide contains guidelines for the presentation of errors in NCHS data for implementation by Center analysts, writers, and reviewers.

"The NCHS Technical Review Program." NCHS Staff Manual Guide, General Progràm Policy No. 2, May 18, 1982.

This guide sets forth the procedures for assuring technical review of the NCHS statistical research projects and intramural research projects.

"Policy Statement - NCHS, On Release of Data for Individual Elementary Units and Special Tabulations." DHEW publication No. (PHS) 78-1212, May 1978.

This document presents a policy position of the National Center for Health Statistics on the dissemination of data for individual persons or establishments reported by respondents to NCHS.

"Clearance for Release of Data Files to Persons Outside NCHS." NCHS Staff Manual Guide, General Administration No. 116, January 6, 1987. 
This guide sets forth the policy and procedures for clearing public use data tapes and other data files, together with their documentation, for release outside the Center.

Mugge, Robert H. "Public Use Data Tapes and Special Tabulations Provided by the NCHS: Fiscal Years 1974 through 1986." Office of the Center Director, National Center for Health Statistics.

These tables show the experience of NCHS in selling public use data tapes, in providing such tapes without charge, and in preparing special tabulations from NCHS data sets. The data provided in these tables cover virtually the entire history of NCHS' data issuance program.

\section{Centers for Disease Control (CDC)}

"CDC Staff Manual on Confidentiality." U.S. DHHS/PHS/CDC, Atlanta, GA 30333. February 1984.

This manual presents the laws, rules, and regulations that exist to require and/or permit the Centers for Disease Control to maintain the confidentiality of records and is modeled after the NCHS confidentiality manual.

CDC also has prepared several memos with instructions for ordering specific reports and manuals of interest.

\section{National Institute for Occupational Safety and Health (NIOSH)}

"NIOSH publications." Fiscal years 84-87.

Included is a listing of NIOSH publications, as well as ordering information and forms.

\section{Health Care Financing Administration (HCFA)}

"Medicare Statistical Files Manual." DHHS/HCFA, Bureau of Data Management and Strategy, Office of Statistics and Data Management April 1987.

This manual provides information about the various statistical files available within HCFA concerning the Medicare program. Also included is an overview of the Medicare program and the data structure that supports it.

Martin, Glenn. "Opening and Controlling Access to Medicare Data." Environmental Epidemiology (Michigan: Lewis Publishers, Inc., 1986).

This paper describes the evolution of HCFA data access policy and amplifies conditions that must be met regarding the Privacy Act of 1974.

"Status of OSDM Data Files Under the Privacy Act."

This memo provides a brief explanation of the privacy restrictions for the public use data tapes. 
"Public Access to Data Research, Evaluation or Epidemiologic Purposes."

Provides an explanation of standards for releasing data, and the process to obtain data.

Federal Register Notice on Research "Routine Use of Data." Vol. 47, No. 198, Oct. 1982.

Federal Register Notice Privacy Act of 1974; New System. "Notification of a New System of Records." Vol. 52, No. 170; Vol. 52, No. 178.

Included are proposals to establish new systems of the following records: "Medicare Hearings and Appeals System," and "Aftercare Evaluation System."

Listing of HCFA public use data tapes, their periods of availability, and their prices.

Sample of the memorandum of understanding used by HCFA when releasing data to other Federal organizations.

Sample of the data release agreement that must be signed if HCFA gives data to an "outside" organization with which it does not have a contract.

\section{National Institutes of Health (NIH)}

DHHS/PHS/NIH Manual Transmittal Sheets: Privacy Act

Sections Include:

1745-13, Privacy Act: EEO Records - Release Date 10/30/78

The effect of the Privacy Act on records generated in the EEO process is discussed in this section.

1745-11 Privacy Act: Social Security Number - Release Date 5/1/78

This section describes the conditions under which social security numbers may be requested, conditions under which such disclosure is mandatory or voluntary, and an individual's rights when requested to disclose his or her social security number.

1745-8 Privacy Act: Mailing Lists - Release Date 9/15/77

This section describes the criteria for determining whether a mailing list is a system of records and establishes policy for the use of mailing lists.

1745-10 Privacy Act: Freedom of Information Act Privacy Act Interface - Release Date $9 / 1 / 77$

This section explains the interrelationship between the FOIA and the Privacy Act. 1745-2 Privacy Act: Establishment/Modification of System of Records - Release Date $6 / 20 / 77$ 
This section describes the procedures to be followed when a system of records is established, modified, or eliminated.

1745-9 Privacy Act: Congressional Inquiries - Release Date 4/15/77

This section describes the procedure for handling congressional inquiries for personal information in a system of records.

1745-4 Privacy Act: Medical/Psychological Records - Release Date 3/15/77

This section describes the policy and procedure for processing requests for access to medical and psychological records.

1745-7 Privacy Act: Fees - Release Date 11/15/76

This section describes the circumstances when NIH may charge fees for copying records and the rate of those fees.

1745-6 Privacy Act: Reporting Requirements - Release Date 11/15/76

This section describes data to be maintained and reported on the operation of systems of records.

"Reference Notebook. Freedom of Information Workshop on Requests for Contract Information." December 1986.

This guide is used to train NIH employees on data dissemination policies of the agency.

Freedom of Information Activities Annual Report for 1986.

\section{Food and Drug Administration (FDA)}

Food and Drug Administration Staff Manual Guide 2460.7 - "Procedures for Implementing the Freedom of Information Act."

This guide provides general and specific procedures for overall FDA implementation of the Freedom of Information Act. The intent of this guide is to supplement HHS' and FDA's Freedom of Information Act preambles and regulations.

Federal Register - Food and Drug Administration. "Public Information." Vol. 39, No. 248, Part II.

This register provides rules and regulations under the Freedom of Information Act (FOIA) pertaining to the FDA's records and information. Policies on disclosure of such information as well as exemptions to the FOIA are stated.

Federal Register - Food and Drug Administration. "Public Information." Vol. 42, No. 10, Part IV.

This register states final regulations regarding public information for the FDA. Title 21 - Food and Drugs. "Part 20 - Public Information." 
"A History of the U.S. National Reporting Program for Mental Health Statistics, 1840-1983." Mental Health Service System Reports, Series No. 3. DHHS:PHS:ADAMHA, National Institute of Mental Health, Division of Biometry and Epidemiology.

This report traces the history of the national reporting program for mental health statistics.

Manderscheid et al., "The National Reporting Program for Mental Health Statistics: History and Findings." Public Health Reports. Vol. 101, No. 5, September-October 1986.

This report describes the history of the national reporting program for mental health statistics. Also included are findings that can be used to describe the development, growth, and evolution of mental health services in the U.S.

Mental Health Service System Reports and Statistical Notes Publication Listing, National Institute of Mental Health, Public Inquiries Branch, January 1987.

Included is a listing of mental health service system reports, mental health statistical notes, and an order form for these publications.

ADAMHA Management Manual Transmittal Sheet. "ADAMHA Freedom of Information Guidelines and Procedures." No. 469, October 1985.

This manual establishes ADAMHA guidelines and procedures for complying with the Freedom of Information Act and with DHHS public information regulations implementing the Act.

\section{Health Resources and Services Administration (HRSA)}

"An Annotated Bibliography of Publications Prepared/Supported by the Office of Data Analysis and Management." DHHS:PHS:HRSA:Bureau of Health Professions, Office of Data Analysis and Management (ODAM) Report No. 1-87, August 1987.

This bibliography lists and briefly describes publications and reports of the Office of Data Analysis and Management, Bureau of Health Professions, HRSA. The publications and reports cited deal primarily with the issues, developments, trends, and projections concerning the Nation's health care personnel.

"The Area Resource File (ARF) System." Information for Health Resources Planning and Research. DHHS:PHS:HRSA, Bureau of Health Professions, Office of Data Analysis and Management, OADM Report No. 4-87, February 1987. 
This manual provides an overview of the Area Resource File System, a detailed presentation of its data organization and content, a description of its products and analytic capabilities, as well as ordering information and an order form for many of its products.

"Fifth Report to the President and Congress on the Status of Health Personnel in the U.S., March 1986. DHHS Pub. No. HRS-P-OD-86-1. DHHS:PHS:HRSA, Bureau of Health Professions.

This report presents information on the number and characteristics of health professions personnel, on the students preparing to enter these fields, and on the institutions in which they are enrolled. In addition, the report describes the important developments and issues currently affecting these health personnel and the possible impact of these trends on health care delivery. It also identifies the data collection and analytical activities that are currently ongoing and the areas in which further information or analyses are needed.

Public Health Service Act Section 332. "Designation of Health Manpower Shortage Areas."

This mandate pertains to data collection for the Bureau of Health Professions, HRSA.

Federal Register. Privacy Act of 1974; New System of Records. "Notification of a new system of records." Vol. 52, No. 177.

This notice establishes a new system of records: "Health Care Practitioner Adverse Credentialing Data Bank"

"Privacy Act Procedures" for Indian Health Service (IHS) Medical Records Staff, all other Persons who work in IHS or Contract Hospitals and Clinics and IHS Contractors Using IHS Medical Records. DHHS:PHS:HRSA:IHS, September 1986.

This manual presents the Indian Health Service's position on the confidentiality and security of individually identifiable medical records. Duties and responsibilities of IHS and contract personnel are stated pursuant to the Privacy Act, to, implementing regulations of DHHS and the PHS, and to Privacy Act policies and procedures developed by IHS staff.

"Indian Health Service Chart Series Book." DHHS:PHS:HRSA:IHS:Office of Planning, Evaluation, and Legislation, Division of Program Statistics, April 1987.

This publication presents information pertaining to the IHS program and its structure, as well as American Indian and Alaska Native demography and patient care. Current and trend information are presented, and comparisons to other population groups are made.

"Clearance of Papers Prepared for Publication." Indian Health Service Circular, No. 84-5. DHHS:PHS:HRSA:IHS, July 16, 1984.

This circular presents procedures for the clearance of scientific and program papers prepared by the IHS staff intended for publication.

Publications Bin Listing of publications for the Indian Health Service, HRSA. 
NCHSR publications: Annotated bibliography, 1983-1985.

Included is a description of NCHSR publications since October 1983.

\section{Miscellaneous}

Pearson, Robert W. "Researchers' Access to U.S. Federal Statistics." Items Social Science Research Council. Vol. 41, No. 1/2, June 1987.

This article discusses several factors that currently threaten researchers' access to Federal statistics. The need to protect such access, while also protecting the confidentiality of those who provide such data, is explored.

"Statistical Policy Working Paper 2, Report on Statistical Disclosure and DisclosureAvoidance Techniques." U.S. Department of Commerce, May 1978.

This report provides methodologies for managerial and technical staff of Federal agencies that release data to achieve appropriate disclosure and disclosureavoidance practices.

"Statistical Policy Handbook, Directive No. 2 and Directive No. 4." U.S. Department of Commerce, May 1978.

This handbook sets forth directives for the conduct of Federal statistical activities. These two directives deal with standards for the publication of statistics and for the prompt compilation and release of statistical information.

"Standards for Discussion and Presentation of Errors in Survey and Census Data." Journal of the American Statistical Association, Vol. 70, No. 351, Part II, September 1975.

This issue presents standards developed by the U.S. Bureau of the Census for informing data users about important limitations in survey and census data due both to sampling and to response and other nonsampling errors.

"Guidelines for Preparation and Review of Statistical Material in Testimony." Office of Health Planning and Evaluation, Office of the Assistant Secretary for Health, March 1983, reissued January 1987.

This staff paper developed by the Division of Data Policy describes minimum guidelines for consideration in the preparation and review of statistical material in PHS testimony.

“Freedom of Information Regulation" U.S. DHHS 45 CFR Part 5, August 1984.

Describes the laws and regulations regarding the Freedom of Information Act. 
"Freedom of Information Activities. Annual Report of the Department of Health and Human Services, 1986."

Federal Register. DHHS, Office of the Secretary. "Availability of Information to the public.” 45 CFR Part 5, Vol. 47, No. 184, September 1982.

This final rule amends the Department's Freedom of Information Act (FOIA) regulations. The rule increases fees for FOI searches and copying to reflect increased costs of the Department. It also establishes guidelines for the waiver or reduction of fees. 
